Please quote as: Janson, A., Söllner, M. \& Leimeister, J. M. (2020). Ladders for Learning: Is Scaffolding the Key to Teaching Problem Solving in Technologymediated Learning Contexts? Academy of Management Learning \& Education (AMLE), 19, 439-468. doi: 10.5465/amle.2018.0078

Copyright: Academy of Management 2019

This is the accepted and unedited paper. The publisher provides the edited paper online (see the link): https://journals.aom.org/doi/10.5465/amle.2018.0078 


\title{
Ladders for Learning: Is Scaffolding the Key to Teaching Problem Solving in \\ Technology-mediated Learning Contexts?
}

\author{
Authors \\ Andreas Janson', Matthias Söllner ${ }^{2,3}$, Jan Marco Leimeister ${ }^{1,3}$ \\ University of Kassel \\ ${ }^{1}$ Information Systems, Research Center for IS Design (ITeG) \\ 2 Information Systems and Systems Engineering \\ E-Mail: [andreas.janson, soellner, leimeister]@uni-kassel.de \\ ${ }^{3}$ University of St. Gallen \\ Institute of Information Management \\ E-Mail: [matthias.soellner, janmarco.leimeister]@unisg.ch
}

\section{ACKNOWLEDGEMENTS:}

The research presented in this paper was partially funded by the German Federal Ministry of Education and Research in the context of the project KoLeArn (www.KoLeArn.de), Grant No. 01BE17008A. The authors are responsible for the content of this publication. We express our gratitude to the students of the University of Kassel who took part in this study. We would also like to thank Marian Thiel de Gafenco for his work and ideas in the early phases of this research project. Furthermore, this research builds on a paper that has been presented at the Academy of Management Annual Meeting 2017 in Atlanta (Janson \& Söllner, 2017). We thank the reviewers and attendees as well as the mentors of the Management Education and Learning Writers Workshop for their valuable feedback that helped us to improve our research and to write this paper. Last but not least, we thank the Associate Editor for his guidance as well as the three anonymous reviewers for their constructive feedback and openness during the review process. 


\begin{abstract}
The success of innovative teaching/learning approaches aiming to foster problem solving in management education depends on useful and easy-to-use IT components in the learning process. However, the complexity of problem solving in self-regulated learning approaches may overwhelm the learner and can lead to unsatisfying learning outcomes. Research suggests the implementation of technology-enhanced scaffolds as a mechanism to guide the learners in their individual problem-solving process to enhance their learning outcomes. We present a theoretical model based on adaptive structuration theory and cognitive load theory that explains how technologyenhanced scaffolding contributes to learning outcomes. We test the model with a fully randomized between-subject experiment in a flipped classroom for management education focusing on individual problem solving. Our results show that technology-enhanced scaffolding contributes significantly to the management of cognitive load as well as to learning process satisfaction and problemsolving learning outcomes. Thereby, our paper provides new conceptual and empirically tested insights for a better understanding of technology-enhanced scaffolds and their design to assist problem solving and its respective effects in flipped classrooms for management education.
\end{abstract}

\title{
Keywords:
}

Technology-mediated Learning; Technology-enhanced Scaffolding; Flipped Classroom; Problem Solving

\section{INTRODUCTION}

With the advent of educational concepts based on information technology (IT), teaching and learning in the management discipline has changed tremendously in the past (Whitaker, New, \& Ireland, 2016). Technology-mediated learning (TML) is an umbrella term for IT in education 
described as "an environment in which the learner's interactions with learning materials (readings, assignments, exercises, etc.), peers, and/or instructors are mediated through advanced information technologies" (Alavi \& Leidner, 2001: 2) to enhance learning outcomes (Alavi, Wheeler, \& Valacich, 1995; Alavi, Yoo, \& Vogel, 1997), facilitate cost advantages (Ghemawat, 2017), and foster the sharing of expertise in global settings (Webster \& Hackley, 1997).

Although there is still a lot of skepticism in management schools concerning the use of IT for teaching (Redpath, 2012; Whitaker et al., 2016), practice highlights the role of efficient TML as a key value proposition (Ghemawat, 2017). This becomes even more relevant for globalized business schools (AACSB International, 2011), since IT can enable a new quality of self-directed, individual learning (Delen, Liew, \& Willson, 2014; Rubin, Fernandes, Avgerinou, \& Moore, 2010), even for problem solving, which is defined as "situated, deliberate, learner-directed, activity-oriented efforts to seek divergent solutions to authentic problems through multiple interactions amongst problem solver, tools, and other resources" (Kim \& Hannafin, 2011b: 405). Problem-solving skills are critical in today's changing society (Winkler, Büchi, \& Söllner, 2019) and are central in management education (Bigelow, 2004; Smith, 2005; Ungaretti, Thompson, Miller, \& Peterson, 2015).

However, research shows that TML lacks features supporting self-regulated learning phases, often resulting in the failure of otherwise innovative education scenarios (Lo \& Hew, 2017). Learners in self-regulated TML approaches have a more active role in the learning process and thus more responsibilities (Söllner, Bitzer, Janson, \& Leimeister, 2018; Wan, Compeau, \& Haggerty, 2012), possibly resulting in large variations of IT use during the learning process (Serva \& Fuller, 2004; Whitaker et al., 2016). One explanation for this observation is the circumstance that studying realworld problems with less support from TML can also result in overwhelmed learners (Kalyuga, 2007). 
Therefore, research suggests the concept of technology-enhanced scaffolding to guide and facilitate the learning process of problem-solving processes in TML (Doering \& Veletsianos, 2007; Gupta \& Bostrom, 2009; Raes, Schellens, Wever, \& Vanderhoven, 2012; Sharma \& Hannafin, 2007; Shin \& Song, 2015). Wood, Bruner, and Ross (1976) describe scaffolding as temporary instructional support for learners to overcome challenges within their zone of proximal development that adjusts the learners' individual learning paths and experiences. With its origin in social constructivist theory (Vygotsky, 1978; Wood et al., 1976), scaffolding posits that intersubjectivity between the instructional designer and the individual learner, as well as between learners, is vital for learning. In practice, there are various ways and rules of thumb to implement technology-enhanced scaffolds (Sharma \& Hannafin, 2007). However, research on the underlying mechanisms, contingencies, and systematic design of technology-enhanced scaffolds and their corresponding effectiveness for leveraging problem-solving is still lacking (Gupta \& Bostrom, 2013; Hannafin, Kim, \& Kim, 2004).

To fill this research gap, we use an experimental approach to answer our research question: How effective is scaffolding as a mechanism when it comes to improving problem-solving outcomes in $T M L$ ? Consequently, the goal of this paper is to investigate how to design technology-enhanced scaffolds and evaluate their effects on the problem-solving skills of management students.

To answer the overarching research question, we conduct a fully randomized experiment. Specifically, we investigate how a theory-motivated design of technology-enhanced scaffolding implemented in a learning management system (LMS) contributes to the learning outcomes of management and business administration students in a flipped IS lecture. To consider IT in the learning process, we take an interdisciplinary view (as suggested by Redpath, 2012) and use adaptive structuration theory (DeSanctis \& Poole, 1994; Poole \& DeSanctis, 1990): a native theory from the IS discipline (Straub, 2012) that has gained first recognition in the management education discipline 
to explain the use of IT in it (Serva \& Fuller, 2004; Whitaker et al., 2016). In addition, we acknowledge the role of cognitive load for the presentation of learning materials that relate to scaffolding TML and problem-solving processes (Paas, Renkl, \& Sweller, 2003a; Sweller, 1988).

Our study's findings contribute to theory by providing a deeper understanding of how the design and use of technology-enhanced scaffolds for problem solving contribute to the outcomes of TML in management education. In addition, we provide an interdisciplinary contribution to adaptive structuration theory and cognitive load theory. From a practitioner's perspective, we provide design implications for how to design and implement technology-enhanced scaffolds in a widely acknowledged open-source LMS that are embedded, for example, in a flipped classroom.

\section{THEORETICAL BACKGROUND AND HYPOTHESES DEVELOPMENT}

This section explains the key concepts of this study: technology-mediated learning, learning management systems, technology-enhanced scaffolding, and the phases of problem solving. It also discusses the two basic theories involved - adaptive structuration theory and cognitive load theory. On this basis, we develop the hypotheses of our study in the following.

\section{Technology-Mediated Learning}

To understand how technology-enhanced scaffolds are embedded in the learning process and relate to learning outcomes, we first briefly look at TML as the overarching concept. Seminal papers on TML from Alavi, Leidner, and colleagues (Alavi, 1994; Alavi et al., 1995; Alavi et al., 1997; Alavi \& Leidner, 2001; Leidner \& Jarvenpaa, 1993; Leidner \& Jarvenpaa, 1995) are often rooted in the IS discipline (Redpath, 2012) and focus on the IT side of educational delivery (Arbaugh, Godfrey, Johnson, Pollack, Niendorf, \& Wresch, 2009). 
TML includes different learning methods (Gupta \& Bostrom, 2009), such as web- or computerbased, asynchronous or synchronous, instructor-led or self-paced, and individual-based or teambased learning (collaborative learning). Modes for blending TML with traditional learning modes (Arbaugh, 2005) as well as the operationalization of epistemological beliefs in TML (Arbaugh \& Benbunan-Finch, 2006) are manifold. Typically, LMS are often used as a the focal IT in the learning process (e.g., Wang, 2017). The role of an LMS is the delivery, assessment, and management of education and training (Islam, 2012), especially to offer an individualized learning process to support users with effective feedback in self-regulated learning phases (Lyons, 2017). However, utilizing IT in the learning process can produce several challenges (Arbaugh, 2014; Wang, 2017). LMSs are often considered as complex IS (Tennant, Mills, \& Chin, 2014) and might therefore overwhelm learners, thus, being not fully exploited concerning the available learning resources and LMS features. In this context, learners, for example, face challenges like missing opportunities to interact with lecturers, therefore indicating the need for support in the learning process (Lo \& Hew, 2017). Further, more complex learning environments draw on problem-solving activities, thus presenting an additional challenge for learners (Arbaugh \& Benbunan-Finch, 2006; Awidi \& Paynter, 2018), since learners might get lost when solving complex tasks and real-world problems without sufficient guidance and support (Hwang, Wu, \& Chen, 2012; Watson \& Sutton, 2012).

\section{Technology-Enhanced Scaffolding for Problem-Solving Activities}

To overcome the challenges of TML in the domain of problem solving and complex learning (Reiser, 2004), we refer to the concept of scaffolding as an influence on the interaction of learners with applied learning methods and structures (Gupta, Bostrom, \& Huber, 2010; Pea, 2004). In traditional learning scenarios not supplemented by IT, these supportive structures are provided by a more knowledgeable other (Wood et al., 1976), such as a teacher or fellow student (peers). 
Scaffolding assists students as a temporary support structure in learning and accomplishing new tasks and concepts. It gradually fades once a learner has successfully completed the tasks and moves on (Pea, 2004). As learners become more independent, confident, and competent, scaffolding measures become less important, and the responsibility for learning then shifts from the instructor to the student (Lepper, Drake, \& O'Donnell-Johnson, 1997). Besides its origins in educational research, the concept of scaffolding with technology is discussed in various contexts (Eryilmaz, Thoms, Mary, Kim, \& Jakko van der Pol, 2015; Huang, Wu, \& Chen, 2012; Kao, Chiang, \& Sun, 2017) but also under similar concepts such as guided exploration (Bell \& Kozlowski, 2008) or adaptive guidance (Bell \& Kozlowski, 2002) when considering the training literature.

Four types of scaffoldings to guide and facilitate the learning process are highlighted in literature: procedural, metacognitive, conceptual, and strategic scaffolds (Hannafin et al., 2004). Table 1 provides a brief definition of these different approaches to scaffolding as well as relevant examples.

Insert Table 1 about here

Scaffolding in TML is provided via technology (Quintana et al., 2004) typically by teachers or instructors (see the examples presented in Table 1) and can be static to dynamic. Static scaffolds do not incorporate the possibility for negotiation between learners and the scaffolding source, while dynamic scaffolds are more interactive and provide the possibility to assess the learners' progress and provide feedback based on the learner context, i.e., the zone of proximal development (Kim \& Hannafin, 2011b). Often, teachers use various technological tools and resources that can assist them in teaching. For instance, wizards as procedural scaffolds can support the learning process by giving advice on how to use the relevant methods and structures (Dinçer \& Doğanay, 2017; Gupta 
\& Bostrom, 2009; Mao \& Brown, 2005), structure tasks (Reiser, 2004), and therefore help to develop consensus on how to utilize the offered learning resources. In contrast, metacognitive scaffolds can support learners, through the explication of the learning goal (Bitzer, Söllner, \& Leimeister, 2016), to monitor their own learning process and learning progress (Molenaar, Chiu, Sleegers, \& van Boxtel, 2011b; Way \& Rowe, 2008). Conceptual scaffolds can support learners to become familiar with TML and help them recognize all elements necessary to overcome learning challenges, e.g., by providing cues or hints to complete a task or by providing thought-provoking feedback in problem-solving processes (Cagiltay, 2006). Therefore, conceptual scaffolds especially contribute to the problematizing mechanism of scaffolding as proposed by Reiser (2004), since they mark critical features related to the task and also highlight discrepancies. Finally, strategic scaffolds further promote problem solving, e.g., by advising how to apply previously acquired knowledge for problem-solving processes.

Concerning the scaffolding purposes outlined above, it is important to note "what to scaffold, when to scaffold, how to scaffold and when to fade scaffolding" (Lajoie, 2005: 542) for designers of technology-enhanced scaffolding interventions. Thus, a large number of studies evaluate their effect in relation to the design purpose of scaffolding in isolation (e.g., Cuevas, Fiore, \& Oser, 2002; Huang et al., 2012; Jumaat \& Tasir, 2016; Molenaar, Chiu, Sleegers, \& van Boxtel, 2011a; Roll, Holmes, Day, \& Bonn, 2012; Wesiak et al., 2014; Yu, Tsai, \& Wu, 2013). In contrast, it is important how the scaffolding design is arranged in the learning process while at the same time keeping the purpose of the scaffold in any phase of the learning process in mind. Pea (2004) illustrates in this context that scaffold designers need to have knowledge of how to scaffold specific steps of inquiry processes by considering the scaffolding purpose. For example, Kim and Hannafin (2011a) 
showed that, for scaffolding problem-solving processes, certain combinations and patterns of scaffolds emerge that are used in inquiry processes. Sharma and Hannafin (2007) also note that scaffolds should be integrated into the learning context and be balanced when, for example, considering the integration of metacognitive and procedural scaffolds.

For scaffolding problem solving, it is crucial to delineate what a problem is (Jonassen, 2000): First, problems are described as unknown entities in situations with a difference between a target state and a current state, e.g., leadership problems in an organization. Second, solving or finding the unknown entity (the problem) has an inherent value, e.g., for an organization. As such, finding the unknown entity relates to the process of solving a problem that "requires a number of complex cognitive operations largely independent of rote learning and factual knowledge" (Greiff \& Neubert, 2014: 38) that relate to knowledge acquisition and knowledge application (Funke, 2001).

Problem-based learning is often used as an overarching teaching approach that is especially prevalent in management education (Bigelow, 2004; Peterson, 2004; Sherwood, 2004; Smith, 2005). It is closely related to other learning concepts such as experiential learning (Arbaugh, DeArmond, \& Rau, 2013) or active learning (Rollag \& Billsberry, 2012; Serva \& Fuller, 2004; Stewart, Houghton, \& Rogers, 2012). Problem solving could relate to the immediate performance for solving problems as well as the transfer of training, which is also referred to as latent learning (Bjork, Dunlosky, \& Kornell, 2013; Schmidt \& Bjork, 1992; Soderstrom \& Bjork, 2015). However, we focus in our study on immediate performance, since knowledge construction during the process of solving problems should also be positively related to latent learning (Dixon \& Brown, 2012; Jacoby, 1978). ${ }^{1}$

\footnotetext{
${ }^{1}$ Latent learning or transfer of training "occurs in the absence of any obvious reinforcement or noticeable behavioral changes" (Soderstrom \& Bjork, 2015: 177). Although latent learning is also important for later performance on the job or an exam, we focus on immediate performance concerning problem-solving learning outcomes because the confounding issues between latent learning and performance are typically related in verbal learning, i.e., memorizing factual knowledge (Soderstrom \& Bjork, 2015), which is not the focus of our study.
} 
The goal of scaffolding is to help students overcome challenges that arise as part of problem-solving activities, such as a lack of motivation, limited understanding of ill-structured problems as well as their inability to control inquiry processes (Beenen \& Arbaugh, 2018; Chen, Lui, \& Martinelli, 2017; Edelson, Gordin, \& Pea, 1999; Kim \& Hannafin, 2011a), to ultimately improve their performance (Xun \& Land, 2004). Kim and Hannafin (2011a) identified therefore five phases of problemsolving: (1) problem identification and engagement, (2) evidence exploration, (3) explanation reconstruction, (4) communication and justification of the explanation, and (5) revision and reflection of the explanation. While there is no general procedure of problem solving (Kim \& Hannafin, 2011b), there are general activities within these five problem-solving phases that can be scaffolded in TML (cf. also the components that of complex problem solving that Funke, 2010 proposes). Figure 1 depicts the phases, inquiry processes and scaffolding foci.

Insert Figure 1 about here

In the first step, students make observations and generate questions. Here, procedural scaffolding could increase the intentionality of, relevance of, and engagement with the identified problem by the provision of authentic and situated contexts, vivid descriptions as well as visualizations (Grossman, Salas, Pavlas, \& Rosen, 2013; Kim \& Hannafin, 2011a, 2011b), which might include presenting the situation in the real business context. The second step involves resource examination, investigation planning, and tool utilization. By providing additional structure to the task through structured work spaces and additional resources, scaffolding may support learners by problematizing the subject matter through offering the possibility to more effectively decompose a problem and organize a problem-solving strategy (Kim, Belland, \& Walker, 2018; Reiser, 2004). Thus, learners might be more satisfied with learning processes as an affective outcome (Krathwohl, 
Bloom, \& Masia, 1964) by perceiving the learning and problem-solving process as more efficient (Gupta \& Bostrom, 2013). In the third step - where students propose answers, explanations, and predictions - scaffolding can help internalize problem-solving tasks. Metacognitive and conceptual scaffolds are designed to help the students reveal misunderstandings within their inquiry process (Kim \& Hannafin, 2011b) and reflect on their own thinking to better understand ill-structured problems (Azevedo \& Hadwin, 2005; Kim et al., 2018), for example, through attentional cueing (Grossman et al., 2013). If students are lost in their learning process due to missing support through scaffolding, i.e., if an impasse of learning occurs, learners may react unsatisfied with the learning process because coordination is missing and inefficiency is perceived (Chandra \& Watters, 2012; Chen, 2010; Kim \& Hannafin, 2011b; Kirschner, Sweller, \& Clark, 2006). In contrast, if technology-enhanced scaffolding is provided, we hypothesize that through the cues highlighted above coordination is triggered and satisfaction as well as problem-solving outcomes are engaged. The fourth step refers to the communication of the results, with a scaffolding focus on, for example, providing feedback with collaborative activities (Jermann \& Dillenbourg, 2008). During the last step - where students justify, defend, and revise ideas or theories (Greiff \& Neubert, 2014; Kim \& Hannafin, 2011a, 2011b) - scaffolding can help students determine their learning level through an ongoing assessment, which means that scaffolding is adapted to the learning level of the students (Kao, Lehman, \& Cennamo, 1996), especially as a more dynamic form of scaffolding.

Thus, the application of a scaffolding concept that contributes to the improvement of students' problem-solving activities can be considered as a significant predictor of learning outcomes in terms of problem solving as well as affective outcomes, such as satisfaction with the learning process by providing a more structured approach to learning. In consequence, we hypothesize: 
HIa: The provision of technology-enhanced scaffolding has a positive effect on problemsolving learning outcomes.

HIb: The provision of technology-enhanced scaffolding has a positive effect on the satisfaction with the learning process.

The positive influence can also be grounded in interdisciplinary research, particularly two theoretical bases: adaptive structuration theory (AST), a native IS theory (Straub, 2012) that is also considered in management education (Serva \& Fuller, 2004; Whitaker et al., 2016); and cognitive load theory, a theory from educational and cognitive psychology (Kirschner et al., 2006) that is also considered in research related to IS (e.g., Hu \& Hu, Han-fen, Fang, Xiao, 2017).

\section{Adaptive Structuration Theory}

When considering IT in the learning process, AST allows the investigation of the relationship between technology and social structures (DeSanctis \& Poole, 1994) and how individuals appropriate IT, for example, in their learning process (Gupta \& Bostrom, 2013), which was also acknowledged by management education (Serva \& Fuller, 2004; Whitaker et al., 2016).

The first premise of AST relates to the influence of structures embedded in a specific context and is defined as the rules, resources, and capabilities in a given context (DeSanctis \& Poole, 1994), i.e., in our context the learning methods and structures that are reflected by the deployment of IT (for example an LMS). In the present paper, the second premise of AST focuses on the learning process. Within this view of learning processes, i.e., problem-solving processes, we acknowledge that learners interact with the structures, such as an LMS in a flipped classroom. During this process of appropriation, learning methods and structures are learned and adapted by individuals or groups 
(Gupta \& Bostrom, 2009). The learning process is in itself a complex phenomenon and is determined by several elements. First, cognitive processes and interactions relating to the appropriation of learning methods influence the learning process. Second, individual differences of learners as well as contextual differences of the learning environment (e.g., the epistemological perspective) influence the process of learning. Third, learning processes are determined by interventions such as support through scaffolding measures (Gupta \& Bostrom, 2009; Whitaker et al., 2016), for instance, through guidance and facilitation of IS appropriation (Dennis, Wixom, \& Vandenberg, 2001). This may be the same for TML (Hwang, Tsai, Chu, Kinshuk, \& Chen, 2012), for example when considering learner control in more open-ended and transfer-oriented tasks, i.e., in our case problem-solving tasks, where scaffolding can limit learner discretion by guidance and support to ensure more effective learning outcomes (Brown, Howardson, \& Fisher, 2016).

Arguing from an AST perspective (DeSanctis \& Poole, 1994; Poole \& DeSanctis, 1990), scaffolding contributes to faithful appropriations (Chin, Gopal, \& Salisbury, 1997) of the provided learning methods. In this context, we define faithfulness as the degree to which learning methods are appropriated consistently with the overall learning goals and epistemological perspective and, in consequence, positively influence the learning success (Gupta \& Bostrom, 2009). Faithful appropriations, for example, occur if learners used an LMS in online learning phases, for instance, through making use of formative assessments to gain a personal understanding if necessary knowledge is missing in relationship to solving the problem (Rietsche, Duss, Persch, \& Söllner, 2018). In such cases, scaffolds can highlight learning goals, making them explicit by situating them in a business context while also cueing and guiding learners through challenging parts of their problem-solving experience. Nevertheless, other appropriations could also be faithful when they ultimately contribute to the proposed learning goals in accordance with the epistemological perspective. In contrast, 
unfaithful appropriations occur for example if learners just take a quiz to memorize the answers, which is not related to filling knowledge gaps necessary to solve a problem. As such, scaffolds may promote more consistent IT use during the learning process, thus leading to a higher degree of faithfulness and learning outcomes (Arbaugh, 2014), for instance, through the explicit guidance that formative assessments are intended to recognize knowledge gaps. On this basis, we hypothesize that technology-enhanced scaffolds directly influence the faithfulness of TML appropriation, and in turn faithfulness directly positively influences learning outcomes:

H2a: The provision of technology-enhanced scaffolding has a positive effect on the faithfulness of appropriation.

H2b: The faithfulness of appropriation has a positive effect on problem-solving learning outcomes.

\section{Cognitive Load Theory}

The cognitive load of learners should be considered when explaining the effects of scaffolding for TML (Liu, Lin, Tsai, \& Paas, 2012). Cognitive load theory (CLT; Miller, 1956; Sweller, 1988) was formulated while trying to understand human problem solving. The insights of CLT are used for instructional design and provide a framework for classifying three types of cognitive load: intrinsic, extraneous, and germane (Danilenko, 2010; Paas et al., 2003a). Intrinsic load represents the inherent difficulty associated with a task, which is dependent only upon the prior knowledge of a learner (Kalyuga, Ayres, Chandler, \& Sweller, 2003). In consequence, intrinsic load cannot be altered by an instructor through changes in the instructional design. Germane load represents the load caused by the construction, automation, and processing of schemas. As such, germane load can be understood as resources of the working memory that are dedicated to information that are germane to learning. In contrast, all other load that does not promote learning is considered as 
extraneous (Kirschner, Ayres, \& Chandler, 2011), which is determined by the manner and complexity learning material is presented. Therefore, extraneous load can be controlled by the instructional design, for example with scaffolding. Since cognitive resources of an individual are limited, extraneous as well as germane load compete for the available cognitive resources. This means, that it is not the goal to minimize cognitive load by utilizing the concept of scaffolding, ${ }^{2}$ rather it is the goal that the load incurred by the instructional design is germane in nature, and, therefore, extraneous load is vice versa decreased (Kirschner et al., 2011). In consequence, scaffolding should keep extraneous load to a minimum so that cognitive resources are used for schema acquisition, hence resulting in higher learning outcomes. Figure 2 illustrates summarizes these assumptions.

Insert Figure 2 about here

When taking the thoughts above into account, scaffolding becomes especially important when considering the complex nature of TML paired with a high degree of learner control in more interactionist learning environments (Brown et al., 2016). As such, LMS oftentimes provides abundant information, learning material as well as other resources that relate to a problem-based learning approach (Sorgenfrei \& Smolnik, 2016). Considering the application of technology-enhanced scaffolds, procedural scaffolds, for example, make learning processes more explicit and structured, and thereby reduce extraneous load in TML. In this context, we define demonstration helpfulness of a learning method as a proxy measure for the level of extraneous load (Ayres \& Youssef, 2008). A

\footnotetext{
${ }^{2}$ The effect of scaffolding on cognitive load can for example be further described through the phenomenon of desirable difficulties (Bjork, Dunlosky, \& Kornell, 2013; Schmidt \& Bjork, 1992; Soderstrom \& Bjork, 2015). Simply put, those difficulties should produce productive failure and therefore influence latent learning and transfer positively (Loibl, Roll, \& Rummel, 2017). If scaffolding would only help to overcome those failures by simply reducing cognitive load at all, effects of scaffolding could be diminished or even detrimental for learning (Holmes, Day, Park, Bonn, \& Roll, 2014). Nonetheless, when taking a more distinct view of cognitive load as highlighted above into account, it is noticeable that scaffolding not contributes to lower levels of cognitive load. Rather, it enables to invest more cognitive capacity (germane load) into the construction, automation and processing of schemas by reducing unnecessary extraneous load (Loibl, Roll, \& Rummel, 2017; Schalk, Schumacher, Barth, \& Stern, 2018).
} 
Higher level of demonstration helpfulness is in this case associated with lower levels of induced extraneous load. Procedural scaffolds might include vivid descriptions of the learning process, or cues and prompts to prior knowledge that contribute to a higher level of demonstration helpfulness in TML. In turn, learners should be able to better process complex information and solve corresponding ill-structured tasks and problems. By positively influencing demonstration helpfulness and germane load, scaffolding contributes to the management of cognitive load in learning situations. Furthermore, we also hypothesize that scaffolding has a mediating impact by acknowledging the direct impact of germane load on learning outcomes.

H3a: The provision of technology-enhanced scaffolding has a positive effect on demonstration helpfulness.

H3b: The provision of technology-enhanced scaffolding has a positive effect on the level of germane load.

H3c: The level of germane load has a positive effect on problem-solving learning outcomes.

Our theoretical model and hypotheses are shown in Figure 3.

Insert Figure 3 about here

\section{RESEARCH METHOD}

\section{Participants}

To evaluate our theoretical model, we conducted an online experiment in a lecture at a European university. The students who participated majored in management and business administration (except for two attendees from a Humanities degree course with management and business 
administration as a minor) and were enrolled in the course "Introduction to Business and Information Systems Engineering". This course is usually attended by 100-150 undergraduates (freshmen). This introductory IS course is designed as a flipped classroom using an LMS as its central tool for the learning process. Students are required to take this course in their first year of university and have no prior experience with the LMS as implemented for this course. Subjects' participation was voluntary and they received a fixed number of extra credits for the course exam as an incentive to participate. 75 students participated in our experiment and we collected 72 valid data sets in total because we had to drop the data sets of three participants since they did not comply with the experimental procedures. Our sample consisted of 35 female students and 37 male students with an average age of 24.53 years. Concerning the representation of this sample, we had an overall number of 141 students enrolled in the course with 99 students participating in the exam. Thus, our sample represents the majority of students in the exam that aimed to complete the course. Due to data privacy regulations set by the university, the students' union executive committee, as well as a data consent form signed by the participants, it is not possible to drill down further on this data or match exam results with experiment results. Table 2 depicts the demographics of our sample.

Insert Table 2 about here

\section{Study Context}

The study was set up in a flipped classroom (Janson, Söllner, \& Leimeister, 2017; Oeste, Lehmann, Janson, \& Leimeister, 2014). This concept interchanges the conventional way of lectures and self-regulated learning. Outside the classroom, students teach themselves the basic knowledge, e.g., using online videos and learning materials to learn the subject matter on their own (Akçayır \& Akçayır, 2018). In class, students focus on understanding, applying, and analyzing the subject 
matter they previously learnt at home (Strayer, 2012). From an epistemological perspective, the course was designed from a constructivist point of view. The learning goals of the course concentrated on technical basics as well as system analysis and design with an emphasis on modeling techniques considering business processes and data models.

Our study's flipped-classroom environment used the open-source LMS Moodle (Moodle Pty Ltd). The lecturer used the LMS to provide learning materials consisting of videos and slides in small units. Learners studied the learning material in their own time and place and, if needed, could repeat the learning process. The LMS guided students through the learning process using learning materials and lecture videos, and various mock exam resources, such as tests and peer assessment features (Lehmann, Söllner, \& Leimeister, 2016; Oeste et al., 2014). Ultimately, using all the knowledge gained, the learners prepared individual solutions for a part of an extensive open-ended free text assignment, which is considered as the problem-solving portion in our study. However, excluded from our study context is the flipped part that is conducted directly in the lecture hall and is not mediated with IT. The evaluation of the experimental procedures and the technology-enhanced scaffolds that are provided in the LMS are described below.

\section{Experimental Procedures and Tasks}

To test the proposed hypotheses, we conducted a fully randomized pretest-posttest control group experiment with a between-subject design in the field. In order to avoid common method variances (CMV), we did not reveal the goal of our study to the test subjects. Instead, we embedded our test assignment in the typical learning process of the course; for the treatment group, we provided a cover story concerning the general development of the university's LMS (Podsakoff, MacKenzie, Lee, \& Podsakoff, 2003). Regarding statistical remedies, we decided not to conduct any tests, since existing tests - such as Harman's single factor test and the unmeasured latent method 
construct (ULMC) technique (Liang, Saraf, Hu, \& Xue, 2007) - have been criticized for not being able to detect CMV (Chin, Thatcher, \& Wright, 2012). In addition, we relied on objective learning outcome measures, which also should prevent CMV in contrast to self-reported learning outcome measures (Benbunan-Fich, 2010; Sitzmann, Ely, Brown, \& Bauer, 2010).

Prior to the semester, all participants completed a brief survey concerning their demographics. Once all participants had self-enrolled for the assignment in the LMS, they performed a cognitive knowledge pretest related to the following problem-solving phases to control for prior knowledge. The pretest consisted of four questions concerning declarative knowledge and four concerning procedural knowledge. After completing the pretest, the learners received the learning material and assignment for engaging with the problem-solving activities related to the task. Before the experiment, we tested the task with four student assistants who had already completed the lecture in prior semesters and now teach tutorials related to business process management. After the test, misunderstandings concerning the task were resolved and the task was adjusted accordingly.

The problem-solving tasks and corresponding activities of the learning process can be classified as complex tasks that relate to higher-order thinking skills according to the original learning goal taxonomy of Bloom (1956) as well as the revised taxonomy of Anderson et al. (2001). When considering the previously introduced conceptualization of (complex) problem-solving components proposed by Funke (2001) and Greiff and Neubert (2014), we highlight the focus of knowledge application in this task, since knowledge acquisition typically takes place beforehand when considering flipped classrooms. In the assignment, the students were first asked to interpret and analyze the weaknesses of a real business process related to a recruiting task in human resources; this was described as a real-world problem in an organization and in addition was visually modeled with the business process model notation (BPMN). Second, they had to develop a new business process 
based on their analysis. Third and finally, the students had to decide why their newly developed business process was reasonable and provide an assessment of the potentials of the new business process. After the students completed the task, which was designed to require about 120 minutes, they uploaded their assignment to the LMS and completed a survey to capture the self-reported measures of our model constructs as well as the control variables.

\section{Design of the Experimental Manipulation}

There were two training conditions: (1) the problem-solving condition (the control group; $\mathrm{n}=38$ ); and (2) the problem-solving plus technology-enhanced scaffolding condition (the treatment group; $n=34$ ). The control group followed the learning process described in the previous section. The learners in the treatment group, after taking the pretest, gained access to the learning materials concerning the problem-solving activities as well as the assignment. They could decide freely how they wanted to use the learning material as well as the other resources in our LMS for solving the problem. After finishing the task, the learners uploaded their assignments and took the post-survey. In conclusion, Figure 4 highlights the overall experimental process of both groups.

Insert Figure 4 about here

For the specific design of the experimental manipulation in the treatment condition, we relied on the problem-solving activities described in the theoretical background section. We focus on the first three phases of problem solving that are solely related to individual problem-solving in the LMS; in our study context, the two last phases are conducted in the flipped part of our lecture and therefore purposely ignored. The experimental manipulation is depicted in Figure 5. 
Insert Figure 5 about here

In the initial problem-solving phase ("problem identification and engagement"), we provided procedural as well as conceptual scaffolds in the experimental manipulation. First, vivid descriptions of the learning process, including the learning goals (Athanassiou, McNett, \& Harvey, 2016), were provided with a short video tutorial concerning the problem-solving process to ensure that the learners appropriate the learning methods more faithfully and manage cognitive load. Thus, the focus was on procedural scaffolding through the facilitation of initial orientation concerning the learning process. Second, by providing such a tutorial, pre-engagement with the task was established and the authentic, situated context of the problem was highlighted (Kim \& Hannafin, 2011b). Thus, problematizing of crucial task aspects as a conceptual scaffold was engaged (Quintana et al., 2004; Reiser, 2004).

In the evidence exploration phase, we provided additional learning materials as conceptual scaffolding directly in the problem-solving space. The problem-solving space itself is a course block in the learning management system, where the problem was particularly solved. In this space, the learners in the treatment condition were provided with shortcuts and additional cues that related to the exploration of these learning materials and how they contribute to the problem-solving process. We note that these learning materials were also provided to the control group - not directly in the particular problem-solving space in the LMS and without the mentioned cues but within the regular course materials on the same page of the course in the learning management system. Therefore, learners in the treatment condition should be guided more efficiently in their learning process and, in consequence, appropriate the provided learning materials more faithfully. In contrast, the control group was provided with a higher degree of learner control, since they had to develop their own 
sensemaking of how to use the provided learning materials and how to appropriate them to successfully solve the problem. In this context, we also integrated several cues as problem-exploration scaffolds for the learning materials that relate to more efficient exploration of the learning materials and the management of cognitive load, especially directing germane load to crucial aspects.

In the explanation reconstruction phase, the learners in the treatment group could first assess their prior knowledge about the assignment with a short knowledge test as a first and foremost metacognitive scaffold to monitor learning processes. This test provided adaptive feedback based on the knowledge level. For example, if learners exhibited low levels of business process management modeling knowledge, adaptive feedback was given with suggestions for related learning materials (Khribi, Jemni, \& Nasraoui, 2009), therefore also focusing on the provision of procedural scaffolding through facilitate navigation in TML. Learners with high levels of prior knowledge were encouraged to solve the assignment as a strategic scaffold, but adaptive feedback with specific cues was faded.

Nonetheless, we also provided the control group with the initial possibility to assess their prior knowledge to rule out that there are confounding issues that relate to the provision of feedback versus no feedback. Therefore, we highlight that all learners were faced with desirable difficulties in the learning process (Bjork, 1994; Soderstrom \& Bjork, 2015). However, only the treatment group received the adaptive feedback consisting of specific cues on how to deal with their difficulties in the learning process and, therefore, repair their failure, while the control group received simple feedback with scores. Thus, we expect that such a manipulation does not simply remove difficulties in learning, it rather leads to more productive failure when difficulties and challenges are present (Holmes, Day, Park, Bonn, \& Roll, 2014; Roll et al., 2012), helping to effectively move 
through the zone of proximal development. Thus, we consider this scaffold as a supportive structure and adaptive guidance (Bell \& Kozlowski, 2002) to avoid an impasse in learning through failure recognition, knowledge gap identification as well as guidance to correct a failure subsequently (Holmes et al., 2014; Metcalfe, 2017; Roll et al., 2012), especially through better resource exploration and a more faithful appropriation of the provided learning methods and structures. This would ultimately lead to better transfer results and better long-term error correction (Finn \& Metcalfe, 2010; Metcalfe, 2017).

Second, as a procedural and metacognitive scaffold, we provided transparent monitoring of the learning process via a learning dashboard along all phases, but especially for the explanation reconstruction phase of the individual problem-solving process. With simple graphical illustrations, the dashboard has mainly two scaffolding purposes. On the one hand, the dashboard highlights what phases the learners have already taken, i.e., to further engage metacognition by fostering awareness and monitoring of learning progress. Second, the dashboard elucidates what learners have to do next in the learning process to provide further assistance for organizing the learning process as a procedural scaffold.

Third, based on the results of a quiz taken after uploading their assignments, the learners were provided accordingly with adaptive feedback as a metacognitive scaffold, i.e., to provide reflection, and strategic scaffold, i.e., to provide strategic assistance for the learning process, with the aim to engage them in working on their shortcomings.

\section{Instrument Development}

To test the proposed hypotheses of our study and to assess the outcomes of the problemsolving activities, we first measured learning outcomes related to problem solving as our main 
dependent variable (Gupta et al., 2010; Gupta \& Bostrom, 2013; Yi \& Davis, 2003). Specifically, we structured the problem-solving task into three subtasks in accordance with the learning goals that were assessed individually and then aggregated them to one problem-solving score.

For the analysis of the problem-solving learning outcomes, the assignments of all learners were assessed by two independent raters within a fully crossed rating (i.e., every rater rated every assignment) design to account for the issues of ill-structured measurement designs (Putka, Le, McCloy, \& Diaz, 2008). Both raters were student teaching assistants and had extensive experience with the learning materials. Both had taught tutorials for the course in multiple previous semesters. Prior to the rating of the group learning outcomes, both raters were trained by the first author in assessing the learning outcomes.

For rating the learning outcomes, we adapted the approach of Yoo, Kanawattanachai, and Citurs (2002) to obtain an integrative score that captures the learning outcomes. We used two dimensions. The first dimension, "differentiation", captures the distinct dimensions of the problem and the solution that the group takes into account. The second dimension, "integration/presentation", refers to the development and presentation of complex connections among differentiated characteristics. For each of the three subtasks, both dimensions were rated individually on a scale ranging from 0 to 3 , with 3 being the highest score for both dimensions and representing high learning outcomes. In line with Yoo et al. (2002), a score of 0 reflects the absence of both dimensions. A score of 1 reflects a moderate differentiation and low integrations and presentations. Scores of 2 reflect differentiation of the solution and use of simple integrations and presentations. Scores of 3 show a comprehensive differentiation of the problem as well as complex integrations and presentations. To ensure that there is no method bias in our analysis, both raters were blind to the treatment. Interrater reliability (IRR; Pearson correlation coefficient; $r=0.892 ; n=72 ; p<.001$ ) as well as inter- 
rater agreement (IRA; weighted Cohen's kappa; $\kappa_{\mathrm{w}}=0.762 ; \mathrm{n}=72 ; \mathrm{p}<0.001$ ) showed very strong reliability and agreement of both raters (LeBreton \& Senter, 2008). Due to the complexity of the rating task, the two raters afterwards resolved any differences on their own by discussing until both agreed on a single consensus score, which was then used for the following results. ${ }^{3}$

Second, we measured all other dependent variables with established scales and, if necessary, adapted the scales to the research context. Specifically, we measured the faithfulness of appropriation with the instrument proposed by Chin et al. (1997), which was adapted to our context by Gupta and Bostrom (2013). Concerning learning process satisfaction as an affective learning outcome (cf. Gupta et al., 2010 for an overview concerning affective outcomes in TML research), we relied on the scales offered by Gupta and Bostrom (2013). The rationale for using this scale relates to the fact that we wanted to account for the satisfaction with the problem-solving process that is provided within the LMS. Thus, we relied on the well-established scale for measuring satisfaction with processes concerned with the use of IT (e.g., Chin et al., 1997) instead of relying on typical measures for affective outcomes and reaction of learners/trainees (e.g., Brown, 2005). For measuring the constructs related to cognitive load, we first measured demonstration helpfulness as a proxy for the measurement of extraneous load, and then we measured germane load with two items. We adopted both constructs from Ayres and Youssef (2008). Although we rely on subjective measures for cognitive load, extant research has shown that such measures are typically reliable and valid while at the same time being more sensitive and far less intrusive than objective measures such as

\footnotetext{
${ }^{3}$ In addition to the IRR, we also computed the IRA to further analyze whether both raters can be considered as perfectly interchangeable (LeBreton \& Senter, 2008). Since the IRA shows that the raters are not perfectly interchangeable but do have a very strong agreement (LeBreton \& Senter, 2008), we used in an additional analysis (see Appendix A for model comparisons) the mean score of both raters as dependent variable in a supplementary model analysis. The results of the additional analysis corroborate the findings of the consensus score rating. Therefore, we are confident that the consensus rating score can be considered as reliable and valid for the further analysis.
} 
physiological measures (cf. for an overview Sweller, Ayres, \& Kalyuga, 2011). All latent constructs with their related indicators and statements are shown in Table 3.

Insert Table 3 about here

In line with previous research related to TML (e.g., Gupta \& Bostrom, 2013; Wan et al., 2012), we controlled for the effects of several variables on the learning outcomes related to problem solving. We specifically included control variables that relate to the individual differences of learners (Bitzer \& Janson, 2014; Gupta et al., 2010), which may influence the outcomes in our study, and we therefore want to control. Concerning individual differences in IT use, we controlled for personal innovativeness in the domain of IT (PIIT, Agarwal \& Prasad, 1998) as well as technology readiness (TRI) with the instrument provided by Parasuraman (2000). Both constructs are used as controls in our study because they may have a significant influence on how learners appropriate TML as well as on the outcomes of using such an application. Regarding individual differences in learning, we controlled for self-regulated learning ability (SRL) as well as self-efficacy (SE) with scales by Pintrich and De Groot (1990). Since all the items for the control variables are adopted from respected literature sources, we refrain from including the relevant statements in the paper.

To evaluate the items of the dependent and control variables, we used a 7-point Likert scale. In addition, the survey participants could select "N/A" if no statement was applicable in order to prevent a tendency toward neutral responses. Furthermore, all items were measured as reflective constructs and previously checked against the guidelines by Jarvis, MacKenzie, and Podsakoff (2003). 


\section{Analysis}

For the analysis, we followed recent guidelines from management educational research (Arbaugh \& Hwang, 2013; Köhler, Landis, \& Cortina, 2017). We applied the variance-based partial least squares (PLS) approach (Chin, 1998; Wold, 1982) in order to evaluate the structural equation model of the present study. We rely on the PLS-SEM approach for the following reasons:

1) PLS is more suitable than covariance-based approaches for identifying and predicting key drivers in structural methods (Hair, Ringle, \& Sarstedt, 2011a; Ringle, Sarstedt, \& Straub, 2012). This is in line with our overarching research goal, i.e., the evaluation of the influence of independent variables on learning outcomes in TML research, i.e., in our case especially the impact of technology-enhanced scaffolding.

2) Since the data collection efforts are embedded in real world TML environments, i.e., in our case a flipped classroom for management education, the sample size of the experimental study is naturally limited by parameters like class size and participation. As such, the PLS approach performs less biased when considering a composite-based data population and a small sample size when utilizing a reflective conceptualization compared to the covariancebased approach, which works best for common factor data populations (Sarstedt, Hair, Ringle, Thiele, \& Gudergan, 2016). ${ }^{4}$ In addition, Appendix A provides additional information

\footnotetext{
${ }^{4}$ For this purpose, we computed the standardized root-mean-square residual (SRMR) for the estimated model (Hu \& Bentler, 1998). Since the SRMR is with a value of 0.161 above the threshold of 0.08 typically used for CB-SEM, we assume in line with Sarstedt, Hair, Ringle, Thiele, and Gudergan (2016) that this points to a composite model population of the underlying data (instead of using the SRMR as a simple model fit measure that may not be applicable to a composite model population at all as pointed out by Hair, Hult, Ringle, Sarstedt, and Thiele (2017)).
} 
that corroborates the findings presented afterwards. ${ }^{5}$ Besides, typical requirements for sample size are fulfilled (Chin, 1998; Hair et al., 2011a; Hair, Hult, Ringle, \& Sarstedt, 2014).

3) PLS-SEM are more suitable for exploratory research than for confirmatory research approaches. Although it is "important to note that the distinction between confirmatory and exploratory is not always as clear-cut as it seems" (Hair et al., 2014: 3), the present model evaluates newly developed hypotheses that have by now not been evaluated in the context of management education and also draw on insights of other fields, such as information systems (e.g., Chin et al., 1997) or educational psychology (e.g,, Paas, Tuovinen, Tabbers, \& van Gerven, 2003b), and are therefore related to explorative research settings (Hair, Hollingsworth, Randolph, \& Chong, 2017). In addition, our experimental manipulation as well as the problem-solving learning outcome measure were not empirically tested before.

4) Identification problems of covariance-based approaches can arise when using single item measures such as manifest variables (Petter, 2018). Therefore, we relied on the PLS approach to better handle especially objective measures such as learning outcome scores, i.e., in our case of the present study problem-solving learning outcome scores.

Thus, we do not take the soft modeling assumptions of the PLS-SEM approach as a carte blanche. Rather we use the PLS-SEM approach for more substantive reasons as pointed out above. We used SmartPLS 3.2.8 as an analysis tool (Ringle, Wende, \& Becker, 2015). Furthermore, SPSS 22 was used for the descriptive analysis and checks concerning the experimental manipulation.

\footnotetext{
${ }^{5}$ Appendix A provides additional information concerning the model evaluation including the model comparison with the consistent PLS (PLSc) algorithm that mimics the common factor model approach such as from CB-SEM (Dijkstra \& Henseler, 2015). The findings in general corroborate the findings from the PLS evaluation.
} 


\section{RESULTS}

\section{Control Variables, Manipulation Check, and Group Comparisons}

We conducted a pretest to assess participants' previous knowledge and included several control variables in our study. The cognitive knowledge pretest and a corresponding t-test for independent samples revealed that previous knowledge did not significantly differ between both groups $(\mathrm{p}>0.1)$. We also included four control variables in the present study, which were incorporated into the model by modeling the influence of the four control variables directly on problemsolving learning outcomes. Except for technology readiness (TRI: $\beta=0.354, p<0.05$ ), none of them had a significant influence on the problem-solving learning outcomes (PIIT: $\beta=-0.003, p>$ $0.05 ;$ SRL: $\beta=0.145, p>0.05 ;$ SE: $\beta=-0.162, p>0.05)$.

Finally, we checked the implemented manipulation in the treatment group. For this purpose, we included three manipulation check items concerning the LMS implementation of the designed scaffolds in the post-test to indicate whether our participants recognized the overall experimental manipulation in the technology-enhanced scaffolding condition. The learners should respond to manipulation checks like "The overview dashboard graphics depicted the learning process clearly in Moodle", "The video tutorial helped me to better organize the learning process" and "The quiz concerning the process analysis was rich in feedback" on a seven-point agreement scale. A multivariate analysis of variance (MANOVA) $[(\mathrm{F}(3,68)=5.425, \mathrm{p}<0.005$; Wilk's $\Lambda=0.807$, partial $\left.\eta^{2}=0.193\right]$ confirmed that the test subjects recognized the experimental manipulation implemented in the treatment condition. Appendix B provides additional statistics of the constructs, items and possible post-hoc analyses concerning group difference in relation to our dependent variables. 


\section{Model Evaluation}

The evaluation of the model follows a two-step approach: first, the evaluation of the outer model, and second, the evaluation of the inner model (Hair, Ringle, \& Sarstedt, 2011b; Hair, Sarstedt, Ringle, \& Mena, 2012; Henseler, Ringle, \& Sinkovics, 2009). In the first step, the outer or measurement model is evaluated to determine its reliability and validity with respect to certain criteria for the latent variables. The evaluation of the inner model and structural dependencies follows in the second step because this evaluation only makes sense if the outer measurement model is sufficiently reliable and valid (Henseler et al., 2009).

The quality criteria of the outer model are presented in Table 4. Indicator reliability was measured with standardized indicator loadings. All indicators load above the minimum value of 0.70 (Hulland, 1999). Internal consistency, which analyzes how indicators reflect the latent variables, was measured by means of construct reliability. This is more appropriate for the PLS procedure since Cronbach's alpha tends to underestimate internal consistency in the course of the PLS approach (Hair et al., 2011b; Hair et al., 2012; Henseler et al., 2009). Values above the threshold of 0.70 indicate that the construct reliability is acceptable for this study and thus substantiate the internal consistency of the latent variables (Bagozzi \& Yi, 1988). Convergent validity was measured using the average variance extracted (AVE), and values above the minimum value of 0.50 indicate that at least half of the variance of a latent construct is explained by the related indicators and therefore acceptable (Bagozzi \& Yi, 1988).

Insert Table 4 about here 
We measured discriminant validity using the Fornell-Larcker criterion, which indicates that the square root of the AVE of a construct should be higher than the correlation of the latent construct with other constructs of the measurement, indicating whether a construct shares more variance with its own indicators than with other constructs (Fornell \& Larcker, 1981). In addition, we assessed the heterotrait-monotrait ratio (HTMT) and the heterotrait-monotrait inference criteria (HTMT infer- $_{\text {- }}$ ence; Henseler, Ringle, \& Sarstedt, 2015). The analysis in Table 5 show that discriminant validity through consideration of the Fornell-Larcker Criterion and the conservative HTMT 85 measure (indicated through all HTMT measures under 0.85) is established. Also, the HTMT inference values are all significantly below the threshold of 1 . Finally, the results of the cross-loadings shown in Table 6 indicate that all indicators load the highest on their own construct (Chin, 1998).

Insert Table 5 about here

Insert Table 6 about here

After the measurement model was shown to be sufficiently reliable and valid, the evaluation of the internal structural model followed. The results of the structural model consist of path coefficients, the coefficient of determination, $\mathrm{R}^{2}$, the significance levels, and effect sizes (Ringle et al., 2012). The results of the structural model are summarized in Figure 6.

Insert Figure 6 about here

Except for the relationship between the scaffolding manipulation and faithfulness of appropriation, all relationships in the structural equation model are significant at least at a level of $\mathrm{p}<0.05$. Thus, 
all hypotheses, except for $\mathrm{H} 2 \mathrm{a}$, are confirmed. According to the value of the path coefficients, the scaffolding manipulation has the highest effect on demonstration helpfulness $(\beta=0.352)$, followed by the effect on germane load $(\beta=0.264)$, problem-solving learning outcomes $(\beta=0.216)$, and finally satisfaction with the learning process $(\beta=0.178)$, therefore confirming H1a, H1b, H3a, and H3b. However, the influence on the faithfulness of appropriation is not significant, disconfirming H2a. Nonetheless, the faithfulness of appropriation has a significant influence on the problemsolving learning outcomes $(\beta=0.171)$, confirming H2b. Finally, the role of cognitive load and its strong effect on learning outcomes is shown by the influence of germane load on problem-solving learning outcomes $(\beta=0.352)$, confirming $\mathrm{H} 3 \mathrm{c}$.

The explained variance of the main endogenous construct - problem-solving learning outcomes can be described as moderate (Hair et al., 2014). The $\mathrm{R}^{2}$ values for the other endogenous constructs are all considered as weak $\left(\mathrm{R}^{2}<0.25\right)$. For the sake of brevity, $\mathrm{R}^{2}$ values are depicted in Figure 6. In a next step, the effect size $\mathrm{f}^{2}$ was measured for the determinants of the problem-solving learning outcomes. The effect size $\mathrm{f}^{2}$ constitutes the influence of exogenous constructs on an endogenous construct by considering the changes in the coefficient of determination, $\mathrm{R}^{2}$ (Cohen, 1988). Values above $0.02,0.15$, and 0.35 indicate a low, moderate, and high effect on the structural level (Henseler et al., 2009). The results therefore indicate that the effects of faithfulness of appropriation $\left(\mathrm{f}^{2}=0.044\right)$ and technology-enhanced scaffolding $\left(\mathrm{f}^{2}=0.057\right)$ can be considered as low, while the effect germane load $\left(\mathrm{f}^{2}=0.139\right)$ has a moderate effect on problem-solving learning outcomes. 


\section{DISCUSSION AND IMPLICATIONS}

\section{Discussion of Findings}

There are several major findings of this study. When comparing the effects of the experimental manipulation, we found significant evidence for the direct influence of technology-enhanced scaffolding on problem-solving learning outcomes, also indicated through the descriptive values of the learning outcome scores (see also Table 4). In addition, scaffolding contributed to learning process satisfaction and the management of cognitive load, as indicated by demonstration helpfulness as well as the level of germane load. We further illustrate the discussion of our findings with selected qualitative insights which we gathered in our post-survey.

When considering the missing learning process intervention in terms of the technology-enhanced scaffolding, learners of the control condition stated that the missing guidance resulted in insecurity and need for more structure (all following quotes translated to English):

"In the end, I had no idea what to write concerning the tasks or how I should approach the solution of the assignment. A little more concrete task would have been nice. I was already insecure when I read the text of the assignment. It would have helped me if there had been a reference of how to approach the task."

"It was very demanding, and the task was not necessarily easy for self-study. It could have been better structured by the teaching staff, especially since it was a partially new topic."

The following two statements of learners from both groups are especially relevant when taking into account learners' other statements related to the time-consuming manner of problem-solving tasks in their own learning process: 
"There was a lot of learning material. Partially, I would have wanted more concrete examples of BPMN. Information was otherwise well prepared and mostly understandable". (Learner in the treatment condition)

"Although the assignment was very extensive, it was provided with helpful and practical examples, in order to understand the topic well." (Learner in the control condition)

These more general statements towards problem solving itself might also relate to the fact that the flipped learning approach was already being used in the undergraduate management education. However, learners might not be accustomed to such learning approaches due to the large-scale lectures typically used in undergraduate studies. Also, multiple learners in both treatment but especially the control group highlighted that they spent multiple hours more than designed on solving the problem. However, we had to recognize privacy regulations and could not measure task time. But when taking the qualitative insights into account, scaffolding might not necessarily contribute to a more effective time management but should also not make learning more time consuming. Nonetheless, learners in the treatment condition especially highlighted the scaffolds in their comments concerning their perceptions of the learning process related to the problem-solving process:

\section{"I found the assistance important to familiarize myself with the working process".}

"I found it to be efficient; everything was very well explained".

However, we did not observe a significant influence of technology-enhanced scaffolding on the faithfulness of appropriation; this may be due to our limited sample size of 72 participants. Larger sample sizes as well as a stronger scaffolding design may be required to detect significant results for scaffolding effects on faithfulness. Nonetheless, the effect of faithfulness of appropriation has 
been proven to directly affect problem-solving learning outcomes. In this context, two learners in the treatment condition highlighted the inhibiting effect of IT in the learning process:

"Very time-consuming and nerve-racking, since the technology was not always cooperative and one was under time pressure."

"I understood the questions very poorly. Computer-based learning is unpleasant for me."

Finally, our findings of the model showed a direct effect of germane load on problem-solving learning outcomes, which has, according to the path coefficient value, the highest effect. This indicates the important role of the management of cognitive load for fostering learning outcomes in problem solving, as also highlighted by a statement from a learner in the control condition:

"It was difficult to cope with the various processes, somehow too much at once. It would have been clearer with a more distributed approach of learning."

Besides the discussion of the discussed theoretical relationships in our model, we also want to highlight that there might be other relationships to discover, as for example indicated through the significant relationships in the correlation matrix of the latent variables (see Table 5), such as between demonstration helpfulness and learning process satisfaction, thus indicating that there may be positive reactions from learners if extraneous load is lowered.

In conclusion, with respect to the results of the study, the findings of our study highlight how important it is to consider cognitive load when imposing complex tasks like real business cases. This is particularly true when simultaneously dealing with TML in the learning process and with undergraduate business students that are typically not accustomed to such high learner control approaches. 


\section{Theoretical Contributions}

Our paper provides several contributions to theory. First, we contribute to the understanding of the effective guidance and facilitation of learning processes in problem-solving for a management education flipped classroom and corresponding self-regulated TML-phases. By providing a deeper understanding of the design and effects of theory-based technology-enhanced scaffolds (Wang \& Hannafin, 2005), we highlight how scaffolding contributes to higher-order learning. These results also contribute to related research fields - such as human-computer interaction - by showing how LMSs can be designed for supporting learning processes.

Second, by building up upon the theoretical lens of AST from IS and sociology, we provide a new view on the determinants of problem solving in TML, thus stressing the importance of studying how learners use and appropriate IT when designing and evaluating TML approaches. As suggested by Tennant et al. (2014), users are not 'passive takers' of complex technology. In this context, technology-enhanced scaffolds could contribute to fostering faithful appropriations and therefore support the learning. Thus, we also contribute to management education and furthering the insights of Whitaker et al. (2016), who also used AST as a guiding framework in their work.

Third, we contribute to CLT and understanding the effects of technology-enhanced scaffolds on the cognitive load in TML and problem solving. We demonstrated that a design that draws on the insights of CLT will lead to higher learning outcomes. Furthermore, our results indicate the superior role of cognitive load in ill-structured, complex tasks that relate to problem-solving activities.

\section{Practical Implications}

The implications for practitioners are considered from various perspectives. First and foremost, we are able to show instructional designers of TML in management education that the 
thoughtful consideration of technology-enhanced scaffolds leads to improvement of learning outcomes when considering the educational concept of a flipped classroom. Although well-designed learning methods and structures are important, guidance and facilitation matters for the success of TML, especially for creating context and situated learning in problem-solving processes (Sherwood, 2004). We show this in a setting particularly prevalent in the management education practice, since we evaluated the effects of the technology-enhanced scaffolds in an undergraduate flipped classroom in a management education setting with a high amount of self-regulated learning parts. These learning contexts are more important than ever in the era of digitization and more selfregulated approaches. Therefore, we indicate the need to consider the thoughtful design of scaffolds to enable the success of an innovative and rising learning method in management education. The need for a thoughtful design of TML is especially prevalent when considering undergraduate business education. Until now, not much attention has been given to purely online delivery modes of TML in undergraduate business education (Arbaugh, 2014), but this is precisely the focus of our study and a first step for an evidence-based TML design.

Second, when business schools want to implement new learning methods such as highly self-regulated approaches with problem-based learning and corresponding learning goals (e.g., flipped classrooms), they should carefully consider how to scaffold the learning process to maximize the outcome. Otherwise, underutilization, cognitive load problems, and, in consequence, low outcomes may impede a promising approach for management education. As Whitaker et al. (2016: 357) states, it is important "to understand how various types of students will use the technology tools, which technology tools are more likely to be used compared with other tools, and which technology tools are more likely to be effective compared with other tools". For instance, executive education should also carefully consider scaffolding learning processes, since executive students might also 
be not accustomed to digital learning environments and according learning processes. In this context, our findings highlight the role of scaffolding when using LMS for management education.

Third, our theory-based design of technology-enhanced scaffolds can serve as a starting point for guiding the instructional design of management courses related to problem-based learning. Such an approach works, for example, with the well-recognized open-source LMS Moodle (Moodle Pty Ltd), without requiring any new plug-ins to be implemented by a university IT department. Rather, the scaffolds used in this study are fully implementable by instructional designers and course administrators without requiring any specific technology knowledge or any additional administrative rights that are often only granted to IT departments. Thus, we indicate for practice that there are scalable and working options to guide and facilitate the learning process with stock LMSs.

\section{LIMITATIONS AND FUTURE RESEARCH}

We acknowledge several limitations to this study, which then underline a demand for future research. There are threats to the validity of the empirical study concerning the generalizability of the results (Bordens \& Abbott, 2011). First, the study is limited to the investigation of technologyenhanced scaffolding in the context of the problem solving by management students in a flipped classroom. There is a need to also consider scaffolds related to collaboratively (Leimeister, 2014) presenting and reflecting on the results of problem solving online completely self-regulated learning approaches, e.g., in MOOCs (Seaton, Bergner, Chuang, Mitros, \& Pritchard, 2014; Wang, Wen, \& Rosé, 2016).

Second, we also acknowledge that the sample in this flipped classroom was rather limited due to self-selection and voluntariness of the study, which is also indicated in general by the difference between course enrollment and exam completion of students. Thus, we acknowledge that there 
might be motivational issues concerning the students overall that could be addressed through motivational scaffolding when considering mandatory scaffolding of problem-solving processes (cf. the meta-analysis of Kim et al., 2018, who indicated the need to consider the evaluation of motivational scaffolding). Nonetheless, we accept the limitations of the sample embedded in a real management flipped classroom consciously to ensure a higher degree of ecological validity.

Third, our study examined the effect of technology-enhanced scaffolding on satisfaction with the learning process and problem-solving learning outcomes; it did not gauge delayed task-related performance such as job or exam performance. Hence, the necessity arises to conduct longitudinal studies investigating how scaffolds contribute to long-term outcomes of TML. However, immediate performance concerning problem solving should also relate to transfer and latent learning (Dixon \& Brown, 2012; Jacoby, 1978) and relates to the fading nature of scaffolding and its effects when considering short vs. long learning episodes (Molenaar, Roda, van Boxtel, \& Sleegers, 2012; Pea, 2004) For instance, in the era of big data, personalized and dynamic scaffolding could provide learners tailored scaffolds (e.g., Bauman \& Tuzhilin, 2018).

Fourth, the control variable of technology-readiness exhibited a significant influence on problemsolving learning outcomes. Therefore, future studies should account for its influence. We also relied on subjective measures for assessing cognitive load. Strategies to enhance the understanding of cognitive load management could involve updated models of cognitive load (Kalyuga, 2011) and should seek to assess extraneous load individually with more objective measures, for example by relying psychophysiological measures or eye-tracking (Conrad \& Bliemel, 2016; Korbach, Brünken, \& Park, 2018), which would also contribute to a better understanding of cognitive load through process data. Considering the survey instrument, we also add to the limitations that we had 
to remove three items of the initial instrument related to the constructs of germane load and satisfaction with the learning process. Thus, future research should check whether the influence of technology-enhanced scaffolding solutions still holds when using the full instrument.

Fifth and finally, we acknowledge that our study does not account for the isolated effects of the different scaffolding purposes. In this context, some scaffolds serve multiple purposes in the learning process. In consequence, future studies should seek to isolate the effects of scaffolding purposes by relying on experimental studies with factorial designs or by theoretically measuring the impact of each scaffolding intervention. In addition, future studies should replicate our findings with confirmatory research efforts to gain more robust insights. ${ }^{6}$ Nevertheless, we highlight that we offer a theory-motivated ensemble of technology-enhanced scaffolding that offers first exploratory insights on the effectiveness for scaffolding problem-solving processes in management education.

\section{CONCLUSION}

Technology-enhanced scaffolding for individual problem solving in innovative TML environments is crucial considering the outcome-oriented application in management education with an emphasis on higher-order learning (e.g., Raes et al., 2012; Young, 1997; Zohar \& Dori, 2003). To evaluate scaffolding outcomes, we followed an experimental approach embedded in an online learning episode in a flipped classroom. First, we derived several hypotheses and developed our research model to model the influence of technology-enhanced scaffolding on problem-solving outcomes, cognitive load management as well as faithfulness of appropriation. Second, we conducted a between-subject pretest-posttest experiment in a flipped classroom that focused on individual problem solving. We designed an experimental manipulation in accordance with theory and

\footnotetext{
${ }^{6}$ Tasks as well as advice on the implementation in the open source LMS Moodle are available upon request for interested researchers to replicate findings in related classroom settings.
} 
implemented it in a university LMS and investigated whether technology-enhanced scaffolding is superior to not providing any specific scaffolding. Our results show the significant influence of technology-enhanced scaffolding on TML outcomes (such as the management of cognitive load) by positively influencing demonstration helpfulness, germane load, learning process satisfaction, as well as problem-solving learning outcomes. In addition, our results highlight the role of IT use in the learning process by showing that the faithfulness of appropriation as well as germane load both have a significant influence on problem-solving learning outcomes.

Our results reveal the need for the greater evaluation of technology-enhanced scaffolding and its effects on TML environments with an emphasis on higher-order learning. Further research, such as design-based studies or systematic experimental approaches - concerning aspects such as the amount, timing, fading, adaptivity, and type of technology-enhanced scaffolding - have to follow in order to deepen our knowledge of scaffolding and its outcomes. 


\section{REFERENCES}

AACSB International 2011. Globalization of management education: Changing international structures, adaptive strategies, and the impact on institutions ; report of the AACSB International Globalization of Management Education Task Force. Bingley, U.K: Emerald.

Agarwal, R., \& Prasad, J. 1998. A Conceptual and Operational Definition of Personal Innovativeness in the Domain of Information Technology. Information Systems Research, 9(2): 204215.

Akçayır, G., \& Akçayır, M. 2018. The flipped classroom: A review of its advantages and challenges. Computers \& Education.

Alavi, M. 1994. Computer-Mediated Collaborative Learning: An Empirical Evaluation. MIS Quarterly, 18(2): 159-174.

Alavi, M., \& Leidner, D. E. 2001. Research Commentary: Technology-Mediated Learning--A Call for Greater Depth and Breadth of Research. Information Systems Research, 12(1): 1-10.

Alavi, M., Wheeler, B. C., \& Valacich, J. S. 1995. Using IT to Reengineer Business Education: An Exploratory Investigation of Collaborative Telelearning. MIS Quarterly, 19(3): 293-312.

Alavi, M., Yoo, Y., \& Vogel, D. R. 1997. Using Information Technology to Add Value to Management Education. The Academy of Management Journal, 40(6): 1310-1333.

Anderson, L. W., Krathwohl, D. R., Airasian, P. W., Cruikshank, K. A., Mayer, R. E., Pintrich, P. R., Raths, J., \& Wittrock, M. C. 2001. A taxonomy for learning, teaching, and assessing: A revision of Bloom's taxonomy of educational objectives, abridged edition.

Arbaugh, J. B. 2005. Is There an Optimal Design for On-Line MBA Courses? Academy of Management Learning \& Education, 4(2): 135-149.

Arbaugh, J. B. 2014. What Might Online Delivery Teach Us About Blended Management Education?: Prior Perspectives and Future Directions. Journal of Management Education, 38(6): 784-817.

Arbaugh, J. B., \& Benbunan-Finch, R. 2006. An Investigation of Epistemological and Social Dimensions of Teaching in Online Learning Environments. Academy of Management Learning \& Education, 5(4): 435-447. 
Arbaugh, J. B., DeArmond, S., \& Rau, B. L. 2013. New Uses for Existing Tools?: A Call to Study On-line Management Instruction and Instructors. Academy of Management Learning \& Education, 12(4): 635-655.

Arbaugh, J. B., \& Hwang, A. 2013. Uses of Multivariate Analytical Techniques in Online and Blended Business Education. Journal of Management Education, 37(2): 229-260.

Arbaugh, J.B., Godfrey, M. R., Johnson, M., Pollack, B. L., Niendorf, B., \& Wresch, W. 2009. Research in online and blended learning in the business disciplines: Key findings and possible future directions. The Internet and Higher Education, 12(2): 71-87.

Athanassiou, N., McNett, J. M., \& Harvey, C. 2016. Critical Thinking in the Management Classroom: Bloom's Taxonomy as a Learning Tool. Journal of Management Education, 27(5): $533-555$.

Awidi, I. T., \& Paynter, M. 2018. The impact of a flipped classroom approach on student learning experience. Computers \& Education.

Ayres, P., \& Youssef, A. 2008. Investigating the influence of transitory information and motivation during instructional animations, Proceedings of the 8th International conference for the learning sciences - Volume 1: 68-75. Utrecht, The Netherlands: International Society of the Learning Sciences.

Azevedo, R., \& Hadwin, A. F. 2005. Scaffolding Self-regulated Learning and Metacognition Implications for the Design of Computer-based Scaffolds. Instructional Science, 33(5-6): 367-379.

Bagozzi, R. P., \& Yi, Y. 1988. On the evaluation of structural equation models. Journal of the Academy of Marketing Science, 16(1): 74-94.

Bauman, K., \& Tuzhilin, A. 2018. Recommending Remedial Learning Material to the Students by Filling their Knowledge Gaps. MIS Quarterly, 42(1): 313-332.

Beenen, G., \& Arbaugh, J. B. 2018. Flipping Class: Why Student Expectations and Person-Situation Fit Matter. Academy of Management Proceedings, 2018(1): 18413. 
Bell, B. S., \& Kozlowski, S. W. J. 2002. Adaptive Guidance:: Enhancing Self-Regulation, Knowledge, and Performance in Technology-Based Training. Personnel Psychology, 55(2): 267-306.

Bell, B. S., \& Kozlowski, S. W. J. 2008. Active learning: Effects of core training design elements on self-regulatory processes, learning, and adaptability. The Journal of applied psychology, 93(2): 296-316.

Benbunan-Fich, R. 2010. Is Self-Reported Learning a Proxy Metric for Learning? Perspectives From the Information Systems Literature. Academy of Management Learning \& Education, 9(2): 321-328.

Bigelow, J. D. 2004. Using Problem-Based Learning to Develop Skills in Solving Unstructured Problems. Journal of Management Education, 28(5): 591-609.

Bitzer, P., \& Janson, A. 2014. Towards a Holistic Understanding of Technology-Mediated Learning Services - a State-of-the-Art Analysis. ECIS 2014 Proceedings.

Bitzer, P., Söllner, M., \& Leimeister, J. M. 2016. Design Principles for High-Performance Blended Learning Services Delivery. Business \& Information Systems Engineering, 58(2): $135-149$.

Bjork, R. A. 1994. Memory and metamemory considerations in the. In J. Metcalfe \& A. Shimamura (Eds.), Metacognition: Knowing about knowing: 185-205. Cambridge, MA, US: MIT Press.

Bjork, R. A., Dunlosky, J., \& Kornell, N. 2013. Self-regulated learning: Beliefs, techniques, and illusions. Annual review of psychology, 64: 417-444.

Bloom, B. S. 1956. Taxonomy of educational objectives: David McKay New York.

Bordens, K. S., \& Abbott, B. B. 2011. Research design and methods: A process approach (8th ed.). New York: McGraw-Hill.

Brown, K. G. 2005. An examination of the structure and nomological network of trainee reactions: A closer look at "smile sheets". The Journal of applied psychology, 90(5): 991-1001. 
Brown, K. G., Howardson, G., \& Fisher, S. L. 2016. Learner Control and e-Learning: Taking Stock and Moving Forward. Annual Review of Organizational Psychology and Organizational Behavior, 3(1): 267-291.

Cagiltay, K. 2006. Scaffolding strategies in electronic performance support systems: Types and challenges. Innovations in Education and Teaching International, 43(1): 93-103.

Chandra, V., \& Watters, J. J. 2012. Re-thinking physics teaching with web-based learning. Computers \& Education, 58(1): 631-640.

Chen, C.-H. 2010. Promoting college students' knowledge acquisition and ill-structured problem solving: Web-based integration and procedure prompts. Computers \& Education, 55(1): 292 303.

Chen, F., Lui, A. M., \& Martinelli, S. M. 2017. A systematic review of the effectiveness of flipped classrooms in medical education. Medical education, 51(6): 585-597.

Chin, W. W., Gopal, A., \& Salisbury, W. D. 1997. Advancing the Theory of Adaptive Structuration: The Development of a Scale to Measure Faithfulness of Appropriation. Information Systems Research, 8(4): 342.

Chin, W. W., Thatcher, J. B., \& Wright, R. T. 2012. Assessing common method bias: Problems with the ULMC technique. MIS Quarterly, 36(3): 1003-1019.

Chin, W.W. 1998. The partial least squares approach for structural equation modeling. In G. A. Marcoulides (Ed.), Modern methods for business research: 295-336. Mahwah, N.J: Lawrence Erlbaum.

Cohen, J. 1988. Statistical power analysis for the behavioral sciences (2nd ed.). Hillsdale, NJ.: Lawrence Erlbaum.

Conrad, C., \& Bliemel, M. 2016. Psychophysiological Measures of Cognitive Absorption and Cognitive Load in E-Learning Applications. ICIS 2016 Proceedings.

Cuevas, H. M., Fiore, S. M., \& Oser, R. L. 2002. Scaffolding cognitive and metacognitive processes in low verbal ability learners: Use of diagrams in computer-based training environments. Instructional Science, 30(6): 433-464. 
Danilenko, E. P. 2010. The relationship of scaffolding on cognitive load in an online self-regulated learning environment: Dissertation.

Delen, E., Liew, J., \& Willson, V. 2014. Effects of interactivity and instructional scaffolding on learning: Self-regulation in online video-based environments. Computers \& Education, 78: $312-320$.

Dennis, A. R., Wixom, B. H., \& Vandenberg, R. J. 2001. Understanding Fit and Appropriation Effects in Group Support Systems via Meta-Analysis. MIS Quarterly, 25(2): 167-193.

DeSanctis, G., \& Poole, M. S. 1994. Capturing the complexity in advanced technology use: Adaptive structuration theory. Organization Science, 5(2): 121-147.

Dijkstra, T., \& Henseler, J. 2015. Consistent Partial Least Squares Path Modeling. MIS Quarterly, 39(2): 297-316.

Dinçer, S., \& Doğanay, A. 2017. The effects of multiple-pedagogical agents on learners' academic success, motivation, and cognitive load. Computers \& Education(111): 74-100.

Dixon, R. A., \& Brown, R. A. 2012. Transfer of Learning: Connecting Concepts during Problem Solving. Journal of Technology Education, 24(1): 2-17.

Doering, A., \& Veletsianos, G. 2007. Multi-Scaffolding Environment: An Analysis of Scaffolding and its Impact on Cognitive Load and Problem-Solving Ability. Journal of Educational Computing Research, 37(2): 107-129.

Edelson, D. C., Gordin, D. N., \& Pea, R. D. 1999. Addressing the Challenges of Inquiry-Based Learning Through Technology and Curriculum Design. Journal of the Learning Sciences, 8(3-4): 391-450.

Eryilmaz, E., Thoms, B., Mary, J., Kim, R., \& Jakko van der Pol 2015. Instructor versus Peer Attention Guidance in Online Learning Conversations. AIS Transactions on Human-Computer Interaction, 7(4): 234-268.

Finn, B., \& Metcalfe, J. 2010. Scaffolding feedback to maximize long-term error correction. Memory \& cognition, 38(7): 951-961.

Fornell, C., \& Larcker, D.F. 1981. Evaluating structural equation models with unobservable variables and measurement error. Journal of Marketing Research, 18(1): 39-50. 
Funke, J. 2001. Dynamic systems as tools for analysing human judgement. Thinking \& Reasoning, 7(1): 69-89.

Funke, J. 2010. Complex problem solving: A case for complex cognition? Cognitive processing, 11(2): 133-142.

Ghemawat, P. 2017. Strategies for Higher Education in the Digital Age. California Management Review, 59(4): 56-78.

Greiff, S., \& Neubert, J. C. 2014. On the relation of complex problem solving, personality, fluid intelligence, and academic achievement. Learning and Individual Differences, 36: 37-48.

Grossman, R., Salas, E., Pavlas, D., \& Rosen, M. A. 2013. Using Instructional Features to Enhance Demonstration-Based Training in Management Education. Academy of Management Learning \& Education, 12(2): 219-243.

Gupta, S., \& Bostrom, R. 2009. Technology-Mediated Learning: A Comprehensive Theoretical Model. Journal of the Association for Information Systems, 10(9): 686-714.

Gupta, S., \& Bostrom, R. 2013. An Investigation of the Appropriation of Technology-Mediated Training Methods Incorporating Enactive and Collaborative Learning. Information Systems Research, 24(2): 454-469.

Gupta, S., Bostrom, R. P., \& Huber, M. 2010. End-user Training Methods: What We Know, Need to Know. SIGMIS Database, 41(4): 9-39.

Hair, J., Hollingsworth, C. L., Randolph, A. B., \& Chong, A. Y. L. 2017. An updated and expanded assessment of PLS-SEM in information systems research. Industrial Management \& Data Systems, 117(3): 442-458.

Hair, J. F., Hult, G. T. M., Ringle, C. M., Sarstedt, M., \& Thiele, K. O. 2017. Mirror, mirror on the wall: A comparative evaluation of composite-based structural equation modeling methods. Journal of the Academy of Marketing Science.

Hair, J. F., Hult, G. T., M., Ringle, C. M., \& Sarstedt, M. 2014. A primer on partial least squares structural equations modeling (PLS-SEM). Los Angeles: Sage.

Hair, J. F., Ringle, C. M., \& Sarstedt, M. 2011a. PLS-SEM: Indeed a Silver Bullet. Journal of Marketing Theory and Practice, 18(2): 139-152. 
Hair, J. F., Ringle, C. M., \& Sarstedt, M. 2011b. The Use of Partial Least Squares (PLS) to Address Marketing Management Topics: From the Special Issue Guest Editors. Journal of Marketing Theory and Practice, 18(2): 135-138.

Hair, J. F., Sarstedt, M., Ringle, C. M., \& Mena, J. A. 2012. An Assessment of the Use of Partial Least Squares Structural Equation Modeling in Marketing Research. Journal of the Academy of Marketing Science, 40(3): 414-433.

Hannafin, M. J., Kim, M. C., \& Kim, H. 2004. Reconciling research, theory, and practice in webbased teaching and learning: The case for grounded design. Journal of Computing in Higher Education, 15(2): 3-20.

Henseler, J., Ringle, C. M., \& Sarstedt, M. 2015. A new criterion for assessing discriminant validity in variance-based structural equation modeling. Journal of the Academy of Marketing Science, 43(1): 115-135.

Henseler, J., Ringle, C. M., \& Sinkovics, R. R. 2009. The Use of Partial Least Squares Path Modeling in International Marketing. In R. R. Sinkovics \& P. N. Ghauri (Eds.), Advances in International Marketing, vol. 20: 277-320. Bingley: Emerald.

Holmes, N. G., Day, J., Park, A. H. K., Bonn, D. A., \& Roll, I. 2014. Making the failure more productive: Scaffolding the invention process to improve inquiry behaviors and outcomes in invention activities. Instructional Science, 42(4): 523-538.

Hu, L.-t., \& Bentler, P. M. 1998. Fit indices in covariance structure modeling: Sensitivity to underparameterized model misspecification. Psychological Methods, 3(4): 424-453.

Hu, P. J.-H., \& Hu, Han-fen, Fang, Xiao 2017. Examining the Mediating Roles of Cognitive Load and Performance Outcomes in User Satisfaction with a Website: A Field Quasi-Experiment. MIS Quarterly, 41(3): 975-987.

Huang, H.-W., Wu, C.-W., \& Chen, N.-S. 2012. The effectiveness of using procedural scaffoldings in a paper-plus-smartphone collaborative learning context. Computers \& Education, 59(2): 250-259.

Hulland, J. 1999. Use of partial least squares (PLS) in strategic management research: a review of four recent studies. Strategic Management Journal, 20(2): 195-204. 
Hwang, G.-J., Tsai, C.-C., Chu, H.-C., Kinshuk, K., \& Chen, C.-Y. 2012. A context-aware ubiquitous learning approach to conducting scientific inquiry activities in a science park. Australasian Journal of Educational Technology, 28(5): 931-947.

Hwang, G.-J., Wu, P.-H., \& Chen, C.-C. 2012. An online game approach for improving students' learning performance in web-based problem-solving activities. Computers \& Education, 59(4): 1246-1256.

Islam, A.K.M. 2012. The Role of Perceived System Quality as Educators' Motivation to Continue E-learning System Use. AIS Transactions on Human-Computer Interaction, 4(1): 2543.

Jackson, S. L., Krajcik, J., \& Soloway, E. 1998. The design of guided learner-adaptable scaffolding in interactive learning environments, Proceedings of the SIGCHI Conference on Human Factors in Computing Systems: 187-194. Los Angeles, California, USA: ACM Press/Addison-Wesley Publishing Co.

Jacoby, L. L. 1978. On interpreting the effects of repetition: Solving a problem versus remembering a solution. Journal of Verbal Learning and Verbal Behavior, 17(6): 649-667.

Janson, A., \& Söllner, M. 2017. How Technology-Enhanced Scaffolding Contributes to ProblemSolving Outcomes in Management Education. Academy of Management Meeting 2017.

Janson, A., Söllner, M., \& Leimeister, J. M. 2017. Individual Appropriation of Learning Management Systems - Antecedents and Consequences. AIS Transactions on Human-Computer Interaction, 9(3): 173-201.

Jarvis, C. B., MacKenzie, S. B., \& Podsakoff, P. M. 2003. A Critical Review of Construct Indicators and Measurement Model Misspecification in Marketing and Consumer Research. Journal of Consumer Research, 30(2): 199-218.

Jermann, P., \& Dillenbourg, P. 2008. Group mirrors to support interaction regulation in collaborative problem solving. Computers \& Education, 51(1): 279-296.

Jonassen, D. H. 2000. Toward a design theory of problem solving. Educational Technology Research and Development, 48(4): 63-85. 
Jumaat, N. F., \& Tasir, Z. 2016. A Framework of Metacognitive Scaffolding in Learning Authoring System Through Facebook. Journal of Educational Computing Research.

Kalyuga, S. 2007. Enhancing Instructional Efficiency of Interactive E-learning Environments: A Cognitive Load Perspective. Educational Psychology Review, 19(3): 387-399.

Kalyuga, S. 2011. Cognitive Load Theory: How Many Types of Load Does It Really Need? Educational Psychology Review, 23(1): 1-19.

Kalyuga, S., Ayres, P., Chandler, P., \& Sweller, J. 2003. The Expertise Reversal Effect. Educational Psychologist, 38(1): 23-31.

Kao, G. Y.-M., Chiang, C.-H., \& Sun, C.-T. 2017. Customizing scaffolds for game-based learning in physics: Impacts on knowledge acquisition and game design creativity. Computers $\&$ Education.

Kao, M. T., Lehman, J. D., \& Cennamo, K. S. 1996. Scaffolding in Hypermedia Assisted Instruction: An Example of Integration, Selected Research and Development Presentations at the 1996 National Convention of the Association for Educational Communications and Technology 1996.

Khribi, M. K., Jemni, M., \& Nasraoui, O. 2009. Automatic Recommendations for E-Learning Personalization Based on Web Usage Mining Techniques and Information Retrieval. Educational Technology \& Society, 12(4): 30-42.

Kim, M. C., \& Hannafin, M. J. 2011a. Scaffolding 6th graders' problem solving in technologyenhanced science classrooms: A qualitative case study. Instructional Science, 39(3): 255282.

Kim, M. C., \& Hannafin, M. J. 2011b. Scaffolding problem solving in technology-enhanced learning environments (TELEs): Bridging research and theory with practice. Computers $\&$ Education, 56(2): 403-417.

Kim, N. J., Belland, B. R., \& Walker, A. E. 2018. Effectiveness of Computer-Based Scaffolding in the Context of Problem-Based Learning for Stem Education: Bayesian Meta-analysis. Educational Psychology Review, 30(2): 397-429. 
Kirschner, P. A., Ayres, P., \& Chandler, P. 2011. Contemporary cognitive load theory research: The good, the bad and the ugly. Computers in Human Behavior, 27(1): 99-105.

Kirschner, P. A., Sweller, J., \& Clark, R. E. 2006. Why Minimal Guidance During Instruction Does Not Work: An Analysis of the Failure of Constructivist, Discovery, Problem-Based, Experiential, and Inquiry-Based Teaching. Educational Psychologist, 41(2): 75-86.

Köhler, T., Landis, R. S., \& Cortina, J. M. 2017. From the Editors: Establishing Methodological Rigor in Quantitative Management Learning and Education Research: The Role of Design, Statistical Methods, and Reporting Standards. Academy of Management Learning \& Education, 16(2): 173-192.

Korbach, A., Brünken, R., \& Park, B. 2018. Differentiating Different Types of Cognitive Load: A Comparison of Different Measures. Educational Psychology Review, 30(2): 503-529.

Krathwohl, D. R., Bloom, B. S., \& Masia, B. B. 1964. The Taxonomy of Educational Objectives: Handbook II, The Affective Domain.

Lajoie, S. P. 2005. Extending the Scaffolding Metaphor. Instructional Science, 33(5-6): 541557.

LeBreton, J. M., \& Senter, J. L. 2008. Answers to 20 Questions About Interrater Reliability and Interrater Agreement. Organizational Research Methods, 11(4): 815-852.

Lehmann, K., Söllner, M., \& Leimeister, J. M. 2016. Design and Evaluation of an IT-based Peer Assessment to Increase Learner Performance in Large-Scale Lectures. ICIS 2016 Proceedings.

Leidner, D., \& Jarvenpaa, S. 1995. The Use of Information Technology to Enhance Management School Education: A Theoretical View. Management Information Systems Quarterly, 19(3).

Leidner, D. E., \& Jarvenpaa, S. L. 1993. The Information Age Confronts Education: Case Studies on Electronic Classrooms. Information systems research, 4(1): 24-54.

Leimeister, J. M. 2014. Collaboration Engineering. Berlin, Heidelberg: Springer Gabler.

Lepper, M. R., Drake, M. F., \& O'Donnell-Johnson, T. 1997. Scaffolding techniques of expert human tutors. In K. H. M. Pressley (Ed.), Scaffolding student learning: Instructional approaches and issues: 108-144. Cambridge, MA, US: Brookline Books. 
Liang, H., Saraf, N., Hu, Q., \& Xue, Y. 2007. Assimilation of enterprise systems: the effect of institutional pressures and the mediating role of top management. MIS Quarterly: 59-87.

Liu, T.-C., Lin, Y.-C., Tsai, M.-J., \& Paas, F. 2012. Split-attention and redundancy effects on mobile learning in physical environments. Computers \& Education, 58(1): 172-180.

Lo, C. K., \& Hew, K. F. 2017. A critical review of flipped classroom challenges in K-12 education: Possible solutions and recommendations for future research. Research and Practice in Technology Enhanced Learning, 12(4): 1-22.

Loibl, K., Roll, I., \& Rummel, N. 2017. Towards a Theory of When and How Problem Solving Followed by Instruction Supports Learning. Educational Psychology Review, 29(4): 693715.

Lyons, R. K. 2017. Economics of the Ed Tech Revolution. California Management Review, 59(4): 49-55.

Mao, J.-Y., \& Brown, B. R. 2005. The Effectiveness of Online Task Support vs. Instructor-Led Training. Journal of Organizational and End User Computing, 17(3): 27-46.

Metcalfe, J. 2017. Learning from Errors. Annual review of psychology, 68: 465-489.

Miller, G. A. 1956. The magical number seven, plus or minus two: Some limits on our capacity for processing information. Psychological review, 63(2): 81-97.

Molenaar, I., Chiu, M. M., Sleegers, P., \& van Boxtel, C. 2011a. Scaffolding of small groups' metacognitive activities with an avatar. International Journal of Computer-Supported Collaborative Learning, 6(4): 601-624.

Molenaar, I., Chiu, M. M., Sleegers, P., \& van Boxtel, C. 2011b. Scaffolding of small groups' metacognitive activities with an avatar. International Journal of Computer-Supported Collaborative Learning, 6(4): 601-624.

Molenaar, I., Roda, C., van Boxtel, C., \& Sleegers, P. 2012. Dynamic scaffolding of socially regulated learning in a computer-based learning environment. Computers \& Education, 59(2): $515-523$.

Moodle Pty Ltd. Moodle - Open-source learning platform | Moodle.org; https://moodle.org/, 14 Jul 2016. 
Oeste, S., Lehmann, K., Janson, A., \& Leimeister, J. M. 2014. Flipping the IS Classroom - Theory-Driven Design for Large-Scale Lectures. ICIS 2014 Proceedings.

Paas, F., Renkl, A., \& Sweller, J. 2003a. Cognitive Load Theory and Instructional Design: Recent Developments. Educational Psychologist, 38(1): 1-4.

Paas, F., Tuovinen, J. E., Tabbers, H., \& van Gerven, P. W. M. 2003b. Cognitive Load Measurement as a Means to Advance Cognitive Load Theory. Educational Psychologist, 38(1): 6371.

Parasuraman, A. 2000. Technology Readiness Index (Tri): A Multiple-Item Scale to Measure Readiness to Embrace New Technologies. Journal of Service Research, 2(4): 307-320.

Pea, R. D. 2004. The Social and Technological Dimensions of Scaffolding and Related Theoretical Concepts for Learning, Education, and Human Activity. Journal of the Learning Sciences, 13(3): 423-451.

Peterson, T. O. 2004. So You're Thinking of Trying Problem Based Learning?: Three Critical Success Factors for Implementation. Journal of Management Education, 28(5): 630-647.

Petter, S. 2018. "Haters Gonna Hate": PLS and Information Systems Research. ACM SIGMIS Database, 49(1): 10-13.

Pintrich, P. R., \& De Groot, E. V. 1990. Motivational and self-regulated learning components of classroom academic performance. Journal of educational psychology, 82(1): 33.

Podsakoff, P.M., MacKenzie, S.B., Lee, J.Y., \& Podsakoff, N.P. 2003. Common method biases in behavioral research: a critical review of the literature and recommended remedies. Journal of applied psychology, 88(5): 879-903.

Poole, M., \& DeSanctis, G. 1990. Understanding the use of Group Decision Support Systems: The Theory of Adaptive Structuration. In J. Fulk \& C. W. Steinfield (Eds.), Organizations and communication theory: 173-193. Newbury Park, Calif.: Sage Publications.

Putka, D. J., Le, H., McCloy, R. A., \& Diaz, T. 2008. Ill-structured measurement designs in organizational research: Implications for estimating interrater reliability. The Journal of applied psychology, 93(5): 959-981. 
Quintana, C., Reiser, B. J., Davis, E. A., Krajcik, J., Fretz, E., Duncan, R. G., Kyza, E., Edelson, D., \& Soloway, E. 2004. A Scaffolding Design Framework for Software to Support Science Inquiry. Journal of the Learning Sciences, 13(3): 337-386.

Raes, A., Schellens, T., Wever, B. de, \& Vanderhoven, E. 2012. Scaffolding information problem solving in web-based collaborative inquiry learning. Computers \& Education, 59(1): 82-94.

Redpath, L. 2012. Confronting the Bias Against On-Line Learning in Management Education. Academy of Management Learning \& Education, 11(1): 125-140.

Reiser, B. J. 2004. Scaffolding Complex Learning: The Mechanisms of Structuring and Problematizing Student Work. Journal of the Learning Sciences, 13(3): 273-304.

Rietsche, R., Duss, K., Persch, J. M., \& Söllner, M. 2018. Design and Evaluation of an IT-based Formative Feedback Tool to Forster Student Performance. ICIS 2018 Proceedings.

Ringle, C. M., Sarstedt, M., \& Straub, D. W. 2012. A Critical Look at the Use of PLS-SEM in MIS Quarterly. MIS Quarterly, 36(1): iii-xiv; s3-s8 (supplement).

Ringle, C. M., Wende, S., \& Becker, J.-M. 2015. SmartPLS 3: SmartPLS GmbH.

Roll, I., Holmes, N. G., Day, J., \& Bonn, D. 2012. Evaluating metacognitive scaffolding in Guided Invention Activities. Instructional Science, 40(4): 691-710.

Rollag, K., \& Billsberry, J. 2012. Technology as the Enabler of a New Wave of Active Learning. Journal of Management Education, 36(6): 743-752.

Rubin, B., Fernandes, R., Avgerinou, M. D., \& Moore, J. 2010. The effect of learning management systems on student and faculty outcomes. The Internet and Higher Education, 13(1-2): $82-83$.

Sarstedt, M., Hair, J. F., Ringle, C. M., Thiele, K. O., \& Gudergan, S. P. 2016. Estimation issues with PLS and CBSEM: Where the bias lies! Journal of Business Research, 69(10): 39984010.

Schalk, L., Schumacher, R., Barth, A., \& Stern, E. 2018. When problem-solving followed by instruction is superior to the traditional tell-and-practice sequence. Journal of educational psychology, 110(4): 596-610. 
Schmidt, R. A., \& Bjork, R. A. 1992. New Conceptualizations of Practice: Common Principles in Three Paradigms Suggest New Concepts for Training. Psychological science, 3(4): 207-218.

Seaton, D. T., Bergner, Y., Chuang, I., Mitros, P., \& Pritchard, D. E. 2014. Who does what in a massive open online course? Communications of the ACM, 57(4): 58-65.

Serva, M. A., \& Fuller, M. A. 2004. Aligning What We Do and What We Measure in Business Schools: Incorporating Active Learning and Effective Media Use in the Assessment of Instruction. Journal of Management Education, 28(1): 19-38.

Sharma, P., \& Hannafin, M. J. 2007. Scaffolding in technology-enhanced learning environments. Interactive Learning Environments, 15(1): 27-46.

Sherwood, A. L. 2004. Problem-Based Learning in Management Education: A Framework for Designing Context. Journal of Management Education, 28(5): 536-557.

Shin, S., \& Song, H.-D. 2015. Finding the optimal scaffoldings for learners' epistemological beliefs during ill-structured problem solving. Interactive Learning Environments, 24(8): 20322047.

Sitzmann, T., Ely, K., Brown, K. G., \& Bauer, K. N. 2010. Self-Assessment of Knowledge: A Cognitive Learning or Affective Measure? Academy of Management Learning \& Education, 9(2): 169-191.

Smith, G. F. 2005. Problem-Based Learning: Can it Improve Managerial Thinking? Journal of Management Education, 29(2): 357-378.

Soderstrom, N. C., \& Bjork, R. A. 2015. Learning versus performance: An integrative review. Perspectives on psychological science : a journal of the Association for Psychological Science, 10(2): 176-199.

Söllner, M., Bitzer, P., Janson, A., \& Leimeister, J. M. 2018. Process is king: Evaluating the performance of technology-mediated learning in vocational software training. Journal of Information Technology, 33(3): 233-253.

Sorgenfrei, C., \& Smolnik, S. 2016. The Effectiveness of E-Learning Systems: A Review of the Empirical Literature on Learner Control. Decision Sciences Journal of Innovative Education, 14(2): 154-184. 
Stewart, A. C., Houghton, S. M., \& Rogers, P. R. 2012. Instructional Design, Active Learning, and Student Performance. Journal of Management Education, 36(6): 753-776.

Straub, D. 2012. Editor's Comments: Does MIS Have Native Theories? Management Information Systems Quarterly, 36(2): iii-xii.

Strayer, J. F. 2012. How learning in an inverted classroom influences cooperation, innovation and task orientation. Learning Environments Research, 15(2): 171-193.

Sun, C.-T., Chen, L.-X., \& Chu, H.-M. 2018. Associations among scaffold presentation, reward mechanisms and problem-solving behaviors in game play. Computers \& Education.

Sweller, J. 1988. Cognitive Load During Problem Solving: Effects on Learning. Cognitive Science, 12(2): 257-285.

Sweller, J., Ayres, P., \& Kalyuga, S. 2011. Cognitive Load Theory. New York, NY: Springer New York.

Tennant, V., Mills, A., \& Chin, W. 2014. A Generalized Darwinism Perspective on Changes in Individuals' Use of Information Systems. ICIS 2014 Proceedings.

Ungaretti, T., Thompson, K. R., Miller, A., \& Peterson, T. O. 2015. Problem-Based Learning: Lessons From Medical Education and Challenges for Management Education. Academy of Management Learning \& Education, 14(2): 173-186.

Vygotsky, L. S. 1978. Mind in society: The development of higher psychological processes: Harvard university press.

Wan, Z., Compeau, D., \& Haggerty, N. 2012. The Effects of Self-Regulated Learning Processes on E-Learning Outcomes in Organizational Settings. Journal of Management Information Systems, 29(1): 307-340.

Wang, F., \& Hannafin, M. J. 2005. Design-based research and technology-enhanced learning environments. Educational Technology Research and Development, 53(4): 5-23.

Wang, F. H. 2017. An exploration of online behaviour engagement and achievement in flipped classroom supported by learning management system. Computers \& Education, 114: 79-91. 
Wang, X., Wen, M., \& Rosé, C. P. 2016. Towards triggering higher-order thinking behaviors in MOOCs. In D. Gašević, G. Lynch, S. Dawson, H. Drachsler \& C. Penstein Rosé (Eds.), Proceedings of the Sixth International Conference on Learning Analytics \& Knowledge: 398 407. New York, NY: ACM.

Watson, S., \& Sutton, J. M. 2012. An Examination of the Effectiveness of Case Method Teaching Online. Journal of Management Education, 36(6): 802-821.

Way, J., \& Rowe, L. 2008. The role of scaffolding in the design of multimedia learning objects. ICME 11 Proceedings.

Webster, J., \& Hackley, P. 1997. Teaching Effectiveness in Technology-Mediated Distance Learning. The Academy of Management Journal, 40(6): 1282-1309.

Wesiak, G., Steiner, C. M., Moore, A., Dagger, D., Power, G., Berthold, M., Albert, D., \& Conlan, O. 2014. Iterative augmentation of a medical training simulator: Effects of affective metacognitive scaffolding. Computers \& Education, 76: 13-29.

Whitaker, J., New, J. R., \& Ireland, R. D. 2016. MOOCs and the Online Delivery of Business Education What's new?: What's not? What now? Academy of Management Learning \& Education, 15(2): 345-365.

Winkler, R., Büchi, C., \& Söllner, M. 2019. Improving Problem-Solving Skills with Smart Personal Assistants: Insights from a Quasi Field Experiment. ICIS 2019 Proceedings.

Wold, H. O. A. 1982. Soft Modeling: The Basic Design and Some Extensions. In K. G. Jöreskog \& H. O. A. Wold (Eds.), Systems under indirect observation. Causality, structure, prediction: 1-54. Amsterdam: North-Holland.

Wood, D., Bruner, J. S., \& Ross, G. 1976. The Role of Tutoring in Problem Solving. Journal of Child Psychology and Psychiatry, 17(2): 89-100.

Xun, G. E., \& Land, S. M. 2004. A conceptual framework for scaffolding III-structured problemsolving processes using question prompts and peer interactions. Educational Technology Research and Development, 52(2): 5-22. 
Yi, M. Y., \& Davis, F. D. 2003. Developing and Validating an Observational Learning Model of Computer Software Training and Skill Acquisition: Information Systems Research. Information systems research, 14(2): 146-169.

Yoo, Y., Kanawattanachai, P., \& Citurs, A. 2002. Forging into the Wired Wilderness: A Case Study of a Technology-Mediated Distributed Discussion-Based Class. Journal of Management Education, 26(2): 139-163.

Young, A. C. 1997. Higher-Order Learning and Thinking: What Is It and How Is It Taught? Educational Technology, 37(4): 38-41.

Yu, F.-Y., Tsai, H.-C., \& Wu, H.-L. 2013. Effects of online procedural scaffolds and the timing of scaffolding provision on elementary Taiwanese students' question-generation in a science class. Australasian Journal of Educational Technology, 29(3): 416-433.

Zohar, A., \& Dori, Y. J. 2003. Higher Order Thinking Skills and Low-Achieving Students: Are They Mutually Exclusive? Journal of the Learning Sciences, 12(2): 145-181. 


\section{TABLE 1}

\section{Description and Examples of Four Types of Scaffolding}

\begin{tabular}{|c|c|c|}
\hline $\begin{array}{l}\text { Scaffolding } \\
\text { Type }\end{array}$ & Description & Example \\
\hline $\begin{array}{l}\text { Procedural } \\
\text { Scaffolds }\end{array}$ & $\begin{array}{l}\text { With emphasis on learning method appropria- } \\
\text { tion, procedural scaffolds encompass ele- } \\
\text { ments that facilitate initial orientation and } \\
\text { navigation in TML (Hannafin et al., 2004). } \\
\text { Consensus is developed primarily between the } \\
\text { instructional designer and the individual user, } \\
\text { and secondarily between the learners. }\end{array}$ & $\begin{array}{l}\text { Procedural structures such as } \\
\text { step-by-step tutorials to provide } \\
\text { guidance for available re- } \\
\text { sources (e.g., Cagiltay, 2006). }\end{array}$ \\
\hline $\begin{array}{l}\text { Metacogni- } \\
\text { tive } \\
\text { Scaffolds }\end{array}$ & $\begin{array}{l}\text { Metacognitive scaffolds focus on learners' } \\
\text { awareness and monitoring of their own learn- } \\
\text { ing progress (Molenaar et al., 2011b; Way \& } \\
\text { Rowe, 2008). Comparing initial goals and in- } \\
\text { dividual results provides valuable information } \\
\text { for instructional designers and learners alike. }\end{array}$ & $\begin{array}{l}\text { Activity-focused prompts for } \\
\text { self-monitoring (e.g., Jumaat \& } \\
\text { Tasir, 2016; Raes et al., 2012). }\end{array}$ \\
\hline $\begin{array}{l}\text { Conceptual } \\
\text { Scaffolds }\end{array}$ & $\begin{array}{l}\text { Conceptual scaffolds support the meaningful } \\
\text { use of TML concerning the underlying di- } \\
\text { dactic intentions. Synergetic concepts become } \\
\text { generally intelligible to the users as they be- } \\
\text { come familiar with the instructional purpose. } \\
\text { Regarding the individual learning objects, } \\
\text { conceptual scaffolds encourage a change of } \\
\text { perspective on given tasks and modify learn- } \\
\text { ers' existing problem-solving strategies (Cag- } \\
\text { iltay, 2006; Way \& Rowe, 2008). }\end{array}$ & $\begin{array}{l}\text { Providing cues concerning pos- } \\
\text { sible paths to a solution of a } \\
\text { problem (e.g., Sun, Chen, \& } \\
\text { Chu, 2018). }\end{array}$ \\
\hline $\begin{array}{l}\text { Strategic } \\
\text { Scaffolds }\end{array}$ & $\begin{array}{l}\text { Strategic scaffolds promote potential prob- } \\
\text { lem-solving strategies (Way \& Rowe, 2008), } \\
\text { both regarding TML use in general and within } \\
\text { concrete learning objects. They help to con- } \\
\text { sider alternative approaches to addressing } \\
\text { problems. Based on preliminary or tentative } \\
\text { solutions, strategic scaffolds prompt students } \\
\text { to consider alternatives to framing, address- } \\
\text { ing, and resolving problems and often involve } \\
\text { different stakeholder perspectives and inter- } \\
\text { pretations (Kim \& Hannafin, 2011b). }\end{array}$ & $\begin{array}{l}\text { Hiding 'complex' learning ma- } \\
\text { terial from novice learners. Af- } \\
\text { ter skill development, more } \\
\text { complex learning materials are } \\
\text { provided to provoke thoughts } \\
\text { concerning alternative problem- } \\
\text { solving approaches (e.g., Jack- } \\
\text { son, Krajcik, \& Soloway, } \\
\text { 1998). }\end{array}$ \\
\hline
\end{tabular}


TABLE 2

Demographics

\begin{tabular}{|l|l|}
\hline Description & Value \\
\hline Gender & $48.6 \%$ \\
\hline Female $(\mathrm{n}=35)$ & $51.4 \%$ \\
\hline Male $(\mathrm{n}=37)$ & \\
\hline Age & 24.53 \\
\hline Mean (S.D. 3.04) & 24 \\
\hline Median & $19-36$ \\
\hline Range & \\
\hline Major & $97.2 \%$ \\
\hline Management and Business Administration $(\mathrm{n}=70)$ & $2.8 \%$ \\
\hline Humanities (n=2) & \\
\hline
\end{tabular}




\section{TABLE 3}

\section{Survey Instrument for Measuring Latent Constructs*}

\begin{tabular}{|c|c|c|c|c|}
\hline $\begin{array}{l}\text { Construct and } \\
\text { Source }\end{array}$ & $\begin{array}{l}\text { Construct } \\
\text { Type }\end{array}$ & Indicator & \multicolumn{2}{|l|}{ Statement } \\
\hline \multirow{4}{*}{$\begin{array}{l}\text { Faithfulness of } \\
\text { Appropriation } \\
\text { Source: Gupta and } \\
\text { Bostrom (2013) }\end{array}$} & \multirow{4}{*}{ Reflective } & Approp1 & \multicolumn{2}{|c|}{ I probably used Moodle improperly. } \\
\hline & & Approp2 & \multicolumn{2}{|c|}{$\begin{array}{l}\text { The instructor of Moodle would view my use } \\
\text { of the system as inappropriate. }\end{array}$} \\
\hline & & Approp3 & \multicolumn{2}{|c|}{$\begin{array}{l}\text { I failed to use Moodle as it should have been } \\
\text { used. }\end{array}$} \\
\hline & & Approp4 & \multicolumn{2}{|c|}{$\begin{array}{l}\text { I did not use Moodle in most appropriate } \\
\text { fashion. }\end{array}$} \\
\hline \multirow{5}{*}{$\begin{array}{l}\text { Satisfaction with } \\
\text { Learning } \\
\text { Process } \\
\text { Source: Gupta and } \\
\text { Bostrom (2013) }\end{array}$} & \multirow{5}{*}{ Reflective } & Sat1 & \multirow{5}{*}{$\begin{array}{l}\text { How would you } \\
\text { describe your } \\
\text { learning process } \\
\text { on a bipolar } \\
\text { scale? }\end{array}$} & Efficient - Inefficient \\
\hline & & Sat2 & & $\begin{array}{l}\text { Coordinated - Uncoordi- } \\
\text { nated }\end{array}$ \\
\hline & & Sat3 & & Satisfying - Dissatisfying \\
\hline & & Sat4** & & Fair - Unfair \\
\hline & & Sat5** & & $\begin{array}{l}\text { Confusing - Understanda- } \\
\text { ble }\end{array}$ \\
\hline \multirow{3}{*}{$\begin{array}{l}\text { Germane Load } \\
\text { Source: Ayres and } \\
\text { Youssef (2008) }\end{array}$} & \multirow{3}{*}{ Reflective } & GL1 & \multicolumn{2}{|c|}{$\begin{array}{l}\text { In studying the assignment, how much men- } \\
\text { tal effort did you invest? }\end{array}$} \\
\hline & & GL2 & \multicolumn{2}{|c|}{$\begin{array}{l}\text { In solving the assignment, how much mental } \\
\text { effort did you invest? }\end{array}$} \\
\hline & & GL3** & \multicolumn{2}{|c|}{$\begin{array}{l}\text { How much did you concentrate when trying } \\
\text { to learn the material? }\end{array}$} \\
\hline \multirow{2}{*}{$\begin{array}{l}\text { Demonstration Help- } \\
\text { fulness } \\
\text { Source: Ayres and } \\
\text { Youssef (2008) }\end{array}$} & \multirow{2}{*}{ Reflective } & DH1 & \multicolumn{2}{|c|}{$\begin{array}{l}\text { How helpful was the demonstration in learn- } \\
\text { ing the material? }\end{array}$} \\
\hline & & DH2 & \multicolumn{2}{|c|}{$\begin{array}{l}\text { How helpful was the demonstration in under- } \\
\text { standing the economics material? }\end{array}$} \\
\hline
\end{tabular}

* Note: Overview of the initial survey instrument.

**Items with two asterisks were dropped due to insufficient indicator loadings and, therefore, did not comply with quality criteria concerning reflective measurement models for PLS. Nonetheless, we highlight that the model with all indicators included holds overall, i.e., all relationships are confirmed that are also confirmed in the final model except for $\mathrm{H} 2 \mathrm{~b}$, which is only marginally significant $(\mathrm{p}<0.1)$ while explained variance drops marginally across constructs. For the sake of brevity, detailed information are available upon request.

Items in italics reverse coded.

All items were rated on a 7-point item Likert-scale. "Faithfulness of Appropriation" was measured with an agreement scale, while "Satisfaction with Learning Process" was measured with a bipolar scale. Germane Load was measured on a scale ranging from "very much" to "very little". Demonstration helpfulness was measured on a scale ranging from "very helpful" to "not helpful at all". 
TABLE 4

Quality Criteria of the Measurement Model*

\begin{tabular}{|c|c|c|c|c|c|}
\hline Construct & Indicator & Loading & AVE & $\begin{array}{l}\text { Composite } \\
\text { Reliability }\end{array}$ & Mean \\
\hline $\begin{array}{l}\text { Technology-Enhanced } \\
\text { Scaffolding }\end{array}$ & $\begin{array}{l}\text { Scaffolding_ } \\
\text { Treatment }\end{array}$ & 1 & I & / & I \\
\hline $\begin{array}{l}\text { Problem-Solving } \\
\text { Learning Outcomes }\end{array}$ & $\begin{array}{l}\text { Learning_ } \\
\text { Outcomes }\end{array}$ & 1 & I & I & $\begin{array}{l}\text { Overall: } 7.29 \\
\text { (S.D. }=3.13 \text { ) } \\
\text { Treatment: } 8.12 \\
\text { (S.D.: } 3.05) \\
\text { Control: } 6.55 \\
\text { (S.D. }=3.06)\end{array}$ \\
\hline \multirow{4}{*}{$\begin{array}{l}\text { Faithfulness of } \\
\text { Appropriation }\end{array}$} & Faith1 & .900 & \multirow{4}{*}{.729} & \multirow{4}{*}{.915} & 5.83 (S.D. = 1.49) \\
\hline & Faith2 & .768 & & & 5.72 (S.D. = 1.56) \\
\hline & Faith3 & .862 & & & $5.62($ S.D. $=1.59)$ \\
\hline & Faith4 & .879 & & & 5.38 (S.D. $=1.87)$ \\
\hline \multirow{3}{*}{$\begin{array}{l}\text { Satisfaction with } \\
\text { Learning Process }\end{array}$} & Sat1 & .802 & \multirow{3}{*}{.721} & \multirow{3}{*}{.885} & 4.26 (S.D. $=1.35)$ \\
\hline & Sat2 & .904 & & & 4.43 (S.D. $=1.28)$ \\
\hline & Sat3 & .838 & & & 3.90 (S.D. = 1.40) \\
\hline \multirow{2}{*}{ Germane Load } & GL1 & .859 & \multirow{2}{*}{.779} & \multirow{2}{*}{.876} & 5.57 (S.D. $=1.18)$ \\
\hline & GL2 & .907 & & & 5.72 (S.D. = 1.09) \\
\hline \multirow{2}{*}{$\begin{array}{l}\text { Demonstration } \\
\text { Helpfulness }\end{array}$} & DH1 & .930 & \multirow{2}{*}{.884} & \multirow{2}{*}{.938} & 4.42 (S.D. = 1.34) \\
\hline & $\mathrm{DH} 2$ & .950 & & & 4.33 (S.D. $=1.31)$ \\
\hline
\end{tabular}

* Note: Technology-enhanced scaffolding and problem-solving learning outcomes were measured as manifest variables with one indicator each. Therefore, AVE and composite reliability could not be computed. 
TABLE 5

Discriminant Validity**

\begin{tabular}{|l|c|c|c|c|c|c|}
\hline Construct & (1) & (2) & (3) & (4) & (5) & (6) \\
\hline (1) Technology-Enhanced Scaffolding & NA & & & & & \\
\hline $\begin{array}{l}\text { (2) Problem-Solving Learning Out- } \\
\text { comes }\end{array}$ & $\begin{array}{c}.332^{*} \\
(.332)\end{array}$ & NA & & & & \\
\hline (3) Faithfulness of Appropriation & .137 & .246 & $\mathbf{. 8 5 4}$ & & & \\
\hline (4) Satisfaction with Learning Process & $.135)$ & $(.260)$ & & & & \\
\hline (5) Germane Load & $(.178)$ & .221 & .203 & $\mathbf{. 8 4 9}$ & & \\
\hline (6) Demonstration Helpfulness & $.264^{*}$ & $.431^{*}$ & $(.246)$ & & & \\
\hline & $(.306)$ & $(.506)$ & $(.140)$ & .149 & $\mathbf{. 8 8 3}$ & \\
\hline
\end{tabular}

** Note: Diagonal elements (in bold) are square roots of the AVE and off-diagonal elements are correlations of the latent variables. The computation of the Fornell-Larcker criterion was omitted for both manifest variables. For the sake of brevity, we did not include control variables in the latent variable correlation table. Asterisk indicates significance of correlation $(\mathrm{p}<0.05)$

Values in parenthesizes show the HTMT criterion, whereby .85 represents a conservative threshold. Therefore, the values show that the conservative HTMT 85 criterion is fully satisfactory and confirming discriminant validity. 
TABLE 6

Cross Loadings*

\begin{tabular}{|c|c|c|c|c|c|c|}
\hline \multirow[b]{2}{*}{ Indicator } & \multicolumn{6}{|c|}{ Construct* } \\
\hline & (1) & (2) & (3) & (4) & (5) & (6) \\
\hline Scaffolding_Treatment & 1 & .332 & .137 & .178 & .264 & .352 \\
\hline Learning_Outcomes & .332 & 1 & .246 & .221 & .431 & .070 \\
\hline Faith1 & .145 & .247 & .900 & .251 & .183 & .260 \\
\hline Faith2 & .063 & .193 & .768 & .074 & .069 & .105 \\
\hline Faith3 & .041 & .188 & .862 & .180 & .001 & .242 \\
\hline Faith4 & .181 & .203 & .879 & .164 & .143 & .202 \\
\hline Sat1 & .106 & .226 & .258 & .802 & .158 & .560 \\
\hline Sat2 & .202 & .176 & .142 & .904 & .152 & .599 \\
\hline Sat3 & .107 & .181 & .155 & .838 & .055 & .466 \\
\hline GL1 & .184 & .356 & .107 & -.025 & .859 & -.065 \\
\hline GL2 & .274 & .402 & .121 & .261 & .907 & .182 \\
\hline DH1 & .302 & .114 & .290 & .644 & .072 & .930 \\
\hline $\mathrm{DH} 2$ & .355 & .025 & .173 & .575 & .077 & .950 \\
\hline
\end{tabular}

Note*:

(1) Technology-Enhanced Scaffolding

(2) Problem-Solving Learning Outcomes

(3) Faithfulness of Appropriation

(4) Satisfaction with Learning Process

(5) Germane Load

(6) Demonstration Helpfulness 


\section{FIGURE 1}

\section{Application of Scaffolding Problem Solving and Scaffolding in this Study (adapted from}

\section{Kim \& Hannafin, 2011a)}

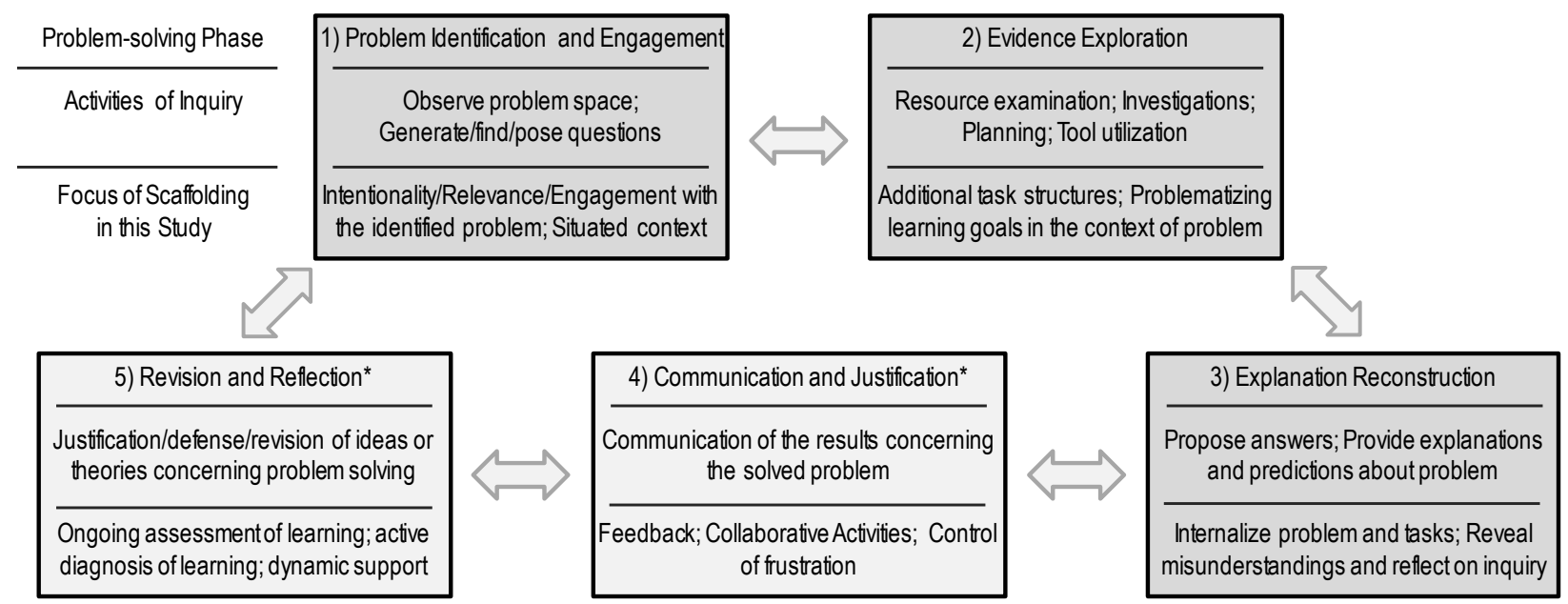

*Light gray phases notaddressed in this study 


\section{FIGURE 2}

\section{Application of Cognitive Load Theory in this Study}

Available CognitiveResources
$\begin{gathered}\text { Fixed by Inherent Difficulty of } \\ \text { Task (In this Study: Complex } \\ \text { Problem-solving Task }\end{gathered}$
$\begin{gathered}\text { Variable and Dependent on } \\ \text { Instructional Design }\end{gathered}$
In this Study: Scaffolding Intervention to Reduce
Extraneous Load (Resulting in Increase of Demonstration
Helpfulness) and to Increase Germane Load
$\vdots$
for the Construction, Automation,
and Processing of Schemas




\section{FIGURE 3}

\section{Theoretical Model}

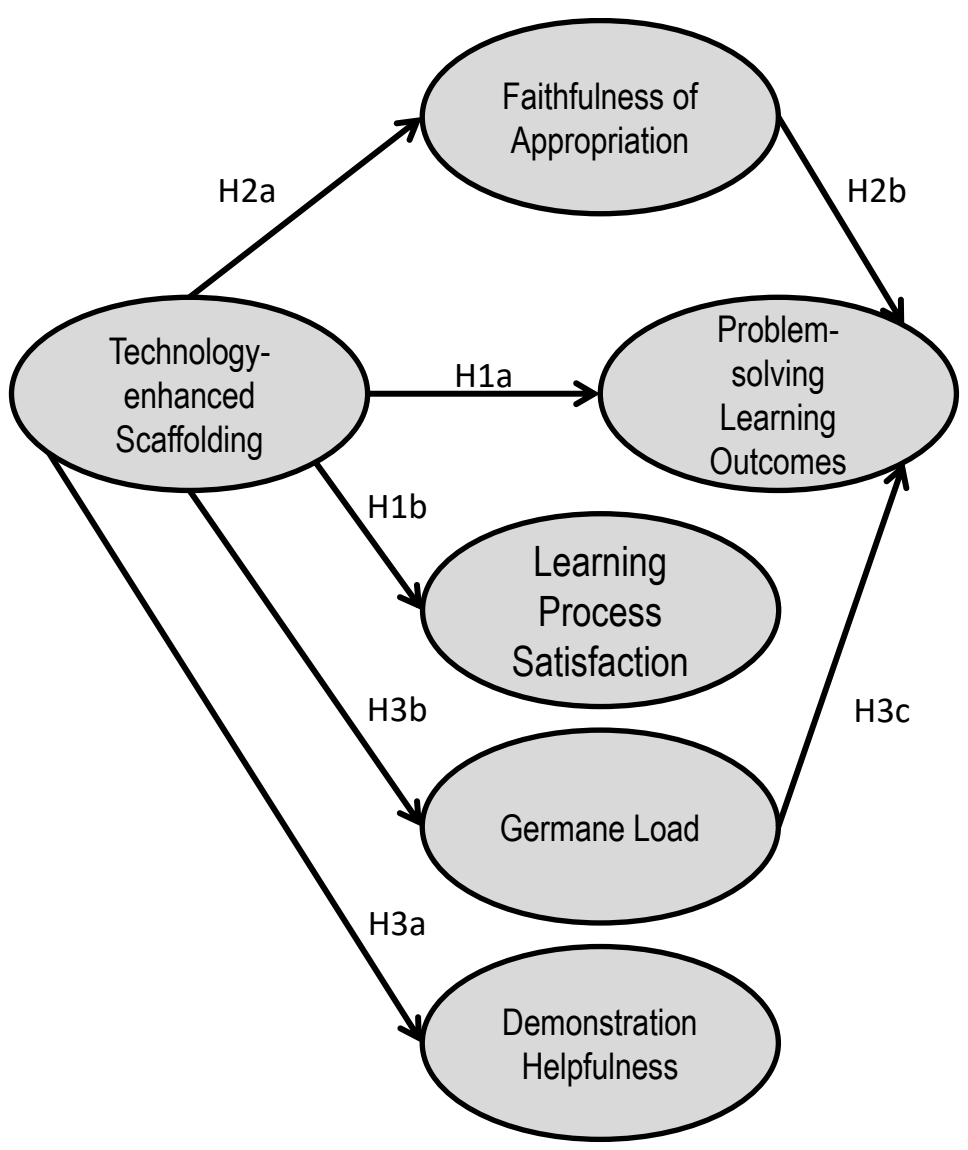




\section{FIGURE 4}

\section{Experimental Process}

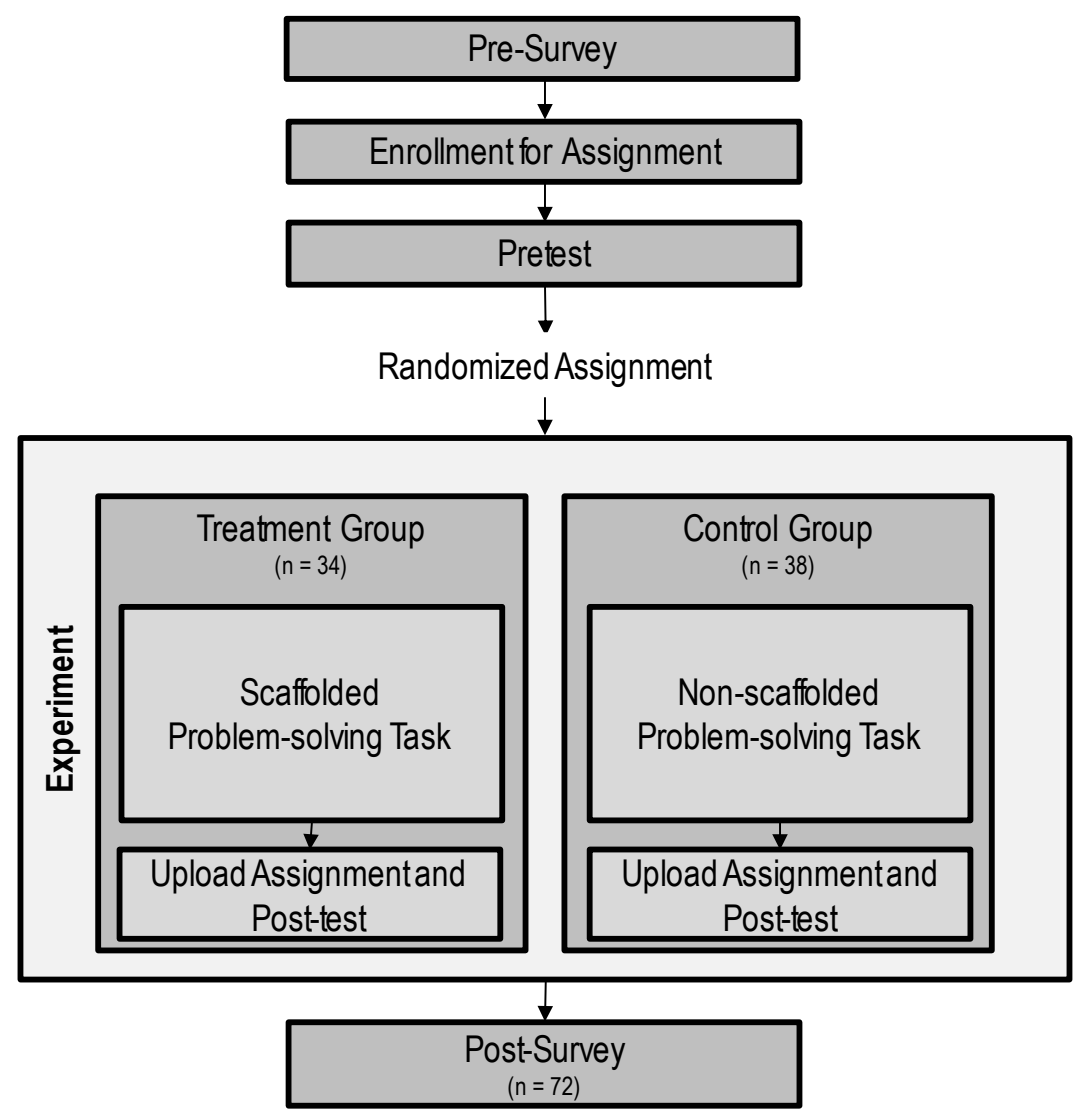




\section{FIGURE 5}

\section{Experimental Manipulation in Problem-solving Process}

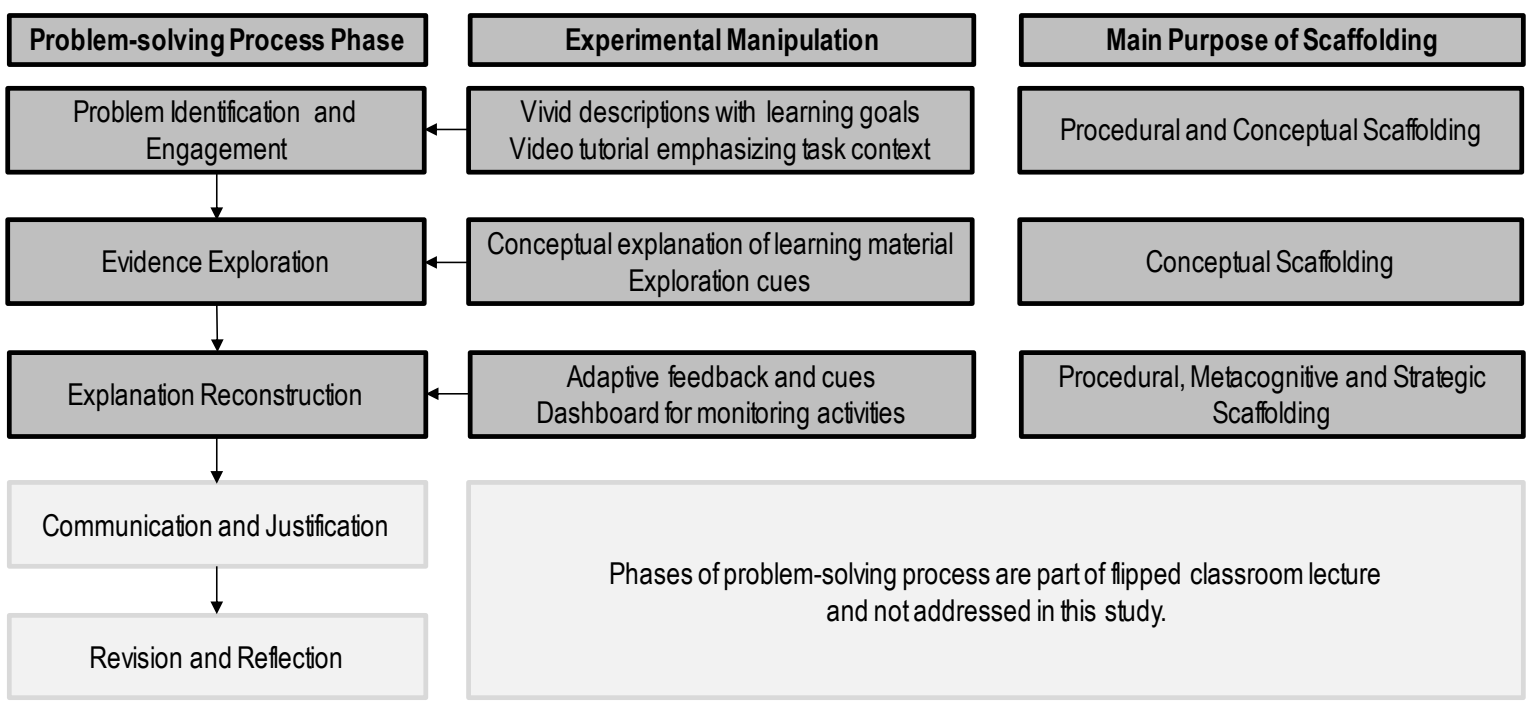




\section{FIGURE 6}

\section{Results of the Structural Model}

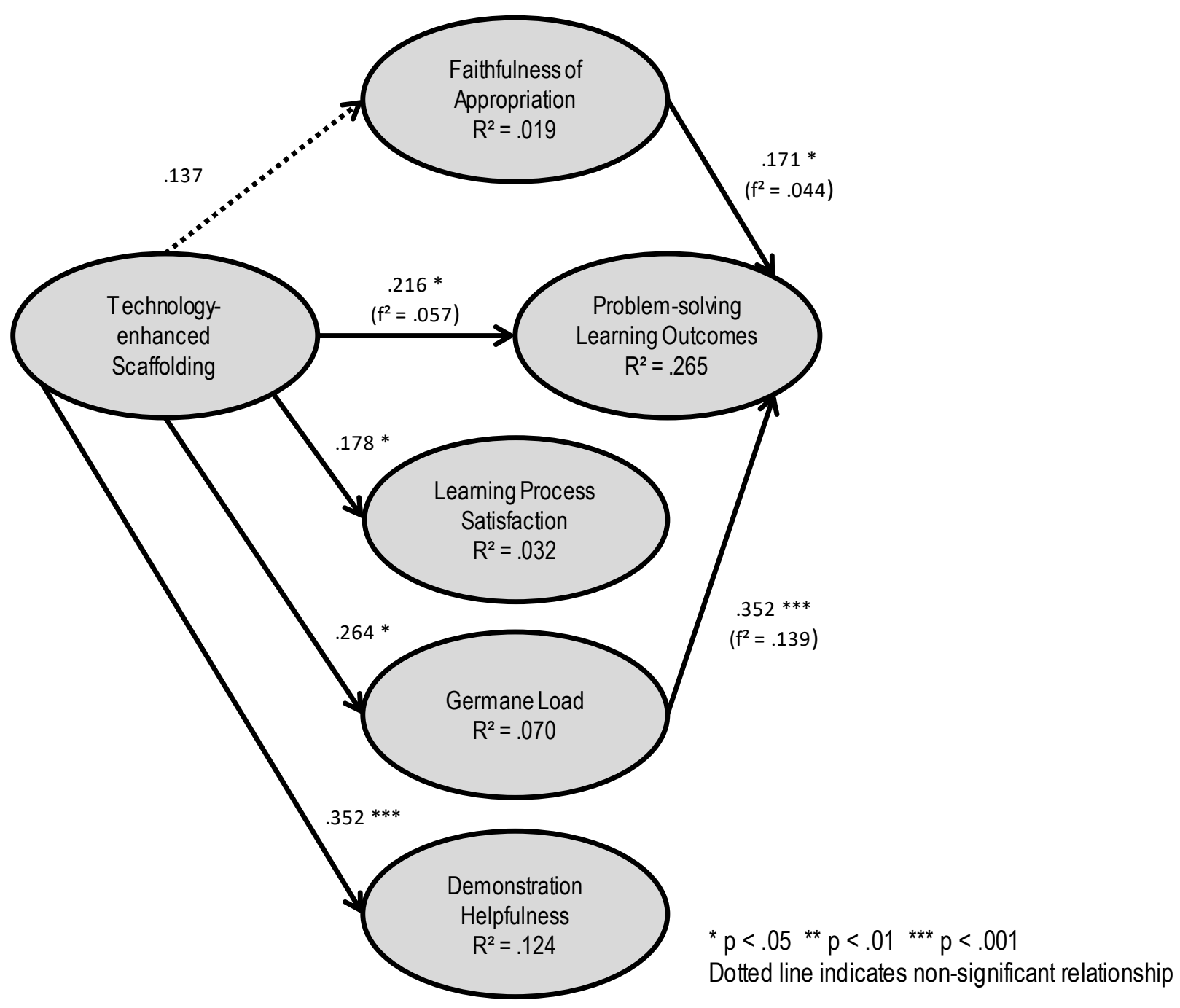




\section{APPENDIX A}

\section{Additional Model Analysis}

To further corroborate the findings of our study, we supplemented the (1) original model analysis with two model comparisons that (2) incorporate the mean score of the two raters concerning the dependent variable problem-solving learning outcomes before a consensus score was accomplished and (3) a model analysis with the consistent PLS (PLSc) algorithm (Dijkstra \& Henseler, 2015) that mimics the common factor model, draws on its assumptions, and, therefore, should produce comparable results to CB-SEM approaches. Concerning the latter, we had to re-specify two constructs of the model ("Faithfulness of Appropriation" and "Germane Load" specified as composites and no applied correction) to account for an inadmissible model solution. Table A1 summarizes the analysis.

\section{TABLE A1}

\section{Results of the Model Comparisons}

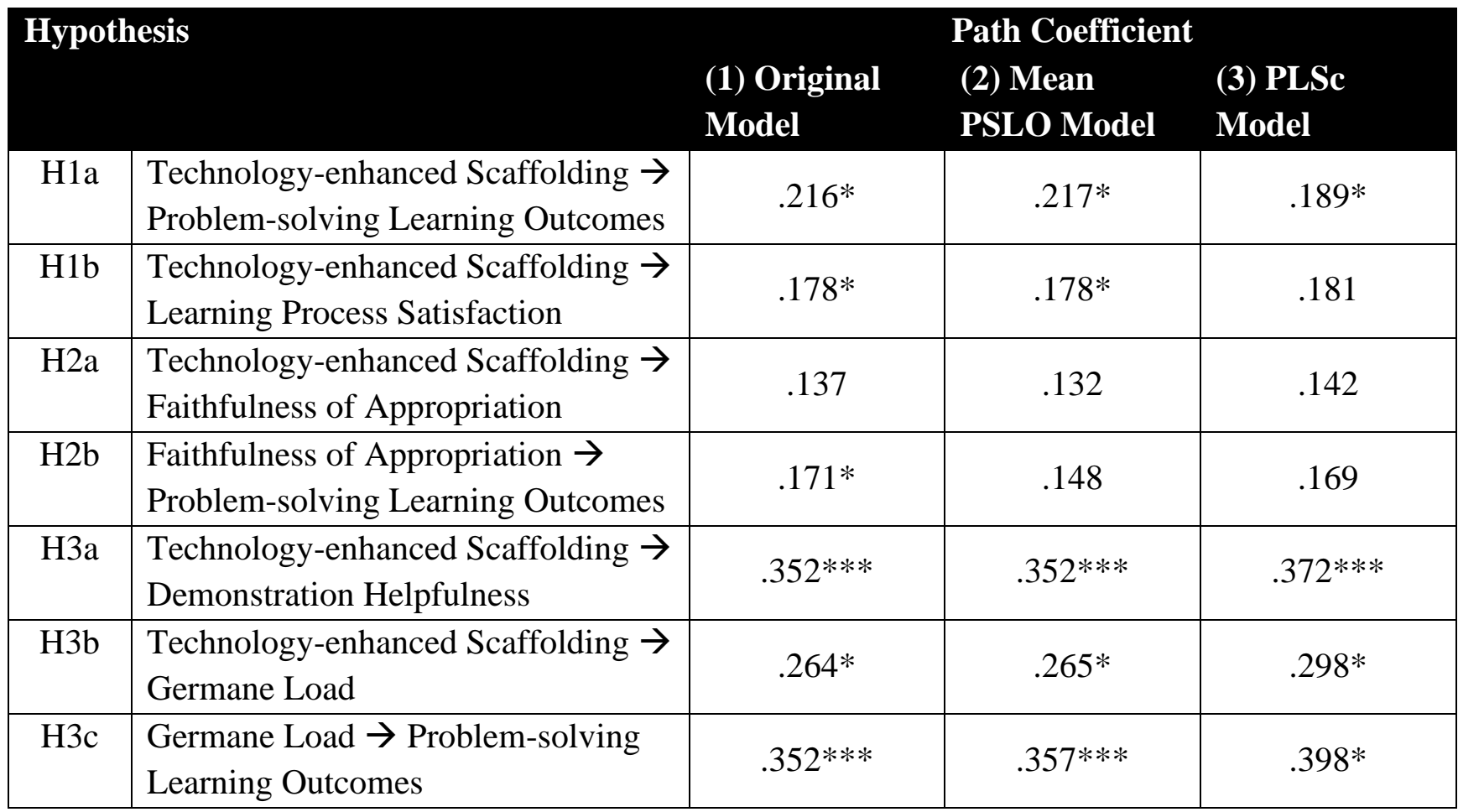


As the additional model analysis shows, the main hypotheses are still confirmed and path coefficients are across all models fairly similar, we only notice that in (2) H2b is not confirmed with a weaker path coefficient, while in (3) in addition $\mathrm{H} 1 \mathrm{~b}$ is not confirmed anymore. Furthermore, we computed the effect size $\mathrm{f}^{2}$ for changes in $\mathrm{R}^{2}$ when comparing the original model (1) with model (2) and (3) with the following procedure for each dependent variable: $\left(\mathrm{R}^{\mathbf{2}}\right.$ additional_model_analysis $-\mathrm{R}^{\mathbf{2}}$ original model $) /\left(1-\mathrm{R}^{2}\right.$ additional_model_analysis $)$. We noticed no effect for all comparisons between (1) and (2), and only a small negative effect size $\left(\mathrm{f}^{2}=-0.054\right)$ for H1a when comparing model (1) and model (3). Thus, the additional analysis provides further evidence for the robust findings of the original model. 


\section{APPENDIX B}

\section{Statistics of Model Constructs, Items and Post-hoc Analyses}

As an additional analysis, Table B1 provides descriptive statistics of our model constructs overall and across both experimental groups. The analysis provides also post-hoc comparisons of all constructs.

Finally, Table B2 provides inter-item correlation statistics with indication of significance.

\section{TABLE B1}

\section{Descriptive Statistics and Post-hoc Group Comparison of Constructs*}

\begin{tabular}{|l|l|l|l|l|}
\multirow{2}{*}{ Construct } & Overall & \multirow{2}{|c|}{ Control Group } & $\begin{array}{l}\text { Treatment } \\
\text { Group }\end{array}$ & \multirow{2}{*}{ p-value } \\
\cline { 2 - 4 } & \multicolumn{2}{|c|}{ Mean/S.D. } \\
\hline $\begin{array}{l}\text { Problem-Solving } \\
\text { Learning Outcomes }\end{array}$ & $\begin{array}{l}7.290 \\
(\text { S.D. }=3.13)\end{array}$ & $\begin{array}{l}6.550 \\
(\text { S.D. }=3.06)\end{array}$ & $\begin{array}{l}8.120 \\
(\text { S.D.: 3.05) }\end{array}$ & \multirow{2}{*}{0.033} \\
\hline $\begin{array}{l}\text { Faithfulness of } \\
\text { Appropriation }\end{array}$ & $\begin{array}{l}5.645 \\
(\text { S.D. }=1.405)\end{array}$ & $\begin{array}{l}5.506 \\
(\text { S.D. }=1.523)\end{array}$ & $\begin{array}{l}5.814 \\
(\text { S.D. }=1.248)\end{array}$ & 0.369 \\
\hline $\begin{array}{l}\text { Satisfaction with } \\
\text { Learning Process }\end{array}$ & $\begin{array}{l}4.198 \\
(\text { S.D. }=1.162)\end{array}$ & $\begin{array}{l}4.105 \\
(\text { S.D. }=1.181)\end{array}$ & $\begin{array}{l}4.312 \\
(\text { S.D. }=1.148)\end{array}$ & 0.467 \\
\hline Germane Load & $\begin{array}{l}5.640 \\
(\text { S.D. }=0.999)\end{array}$ & $\begin{array}{l}5.408 \\
(\text { S.D. }=1.006)\end{array}$ & $\begin{array}{l}5.933 \\
(\text { S.D. }=0.926)\end{array}$ & 0.030 \\
\hline $\begin{array}{l}\text { Demonstration } \\
\text { Helpfulness }\end{array}$ & $\begin{array}{l}4.377 \\
(\text { S.D. }=1.250)\end{array}$ & $\begin{array}{l}4,839 \\
(\text { S.D. }=1 .)\end{array}$ & S.D. $=0.986)$ & 0.005 \\
\hline
\end{tabular}

* Note: Constructs were computed as composite scores in isolation of PLS analysis. 
TABLE B2

Inter-Item Correlation

\begin{tabular}{|c|c|c|c|c|c|c|c|c|c|c|c|c|c|}
\hline \multirow[b]{2}{*}{ Indicator } & \multicolumn{13}{|c|}{ Construct } \\
\hline & (1) & (2) & (3) & (4) & (5) & (6) & (7) & (8) & (9) & (10) & (11) & (12) & (13) \\
\hline $\begin{array}{l}\text { (1) Scaffold- } \\
\text { ing_Treatment }\end{array}$ & 1 & $.332 * *$ & .145 & .063 & .041 & .181 & .106 & .202 & .107 & .184 & $.274^{*}$ & $.302 *$ & $.355 * *$ \\
\hline $\begin{array}{l}\text { (2) Learning_Out- } \\
\text { comes }\end{array}$ & $.332 * *$ & 1 & .247 & .193 & .188 & .203 & .226 & .176 & .181 & $.356 * *$ & $.402 * *$ & .114 & .025 \\
\hline (3) Faith1 & .145 & .247 & 1 & $.582 * *$ & $.688 * *$ & $.730 * *$ & $.264^{*}$ & .201 & .198 & .132 & .187 & $.294 *$ & .202 \\
\hline (4) Faith2 & .063 & .193 & $.582 * *$ & 1 & $.626 * *$ & $.511 * *$ & .126 & .043 & .042 & .125 & .008 & .113 & .087 \\
\hline (5) Faith3 & .041 & .188 & $.688 * *$ & $.626 * *$ & 1 & $.703 * *$ & .225 & .106 & .177 & .008 & -.006 & $.306^{*}$ & .160 \\
\hline (6) Faith4 & .181 & .203 & $.730 * *$ & $.511 * *$ & $.703 * *$ & 1 & .246 & .108 & .101 & .082 & .164 & $.262 *$ & .129 \\
\hline (7) Sat1 & .106 & .226 & $.264^{*}$ & .126 & .225 & .246 & 1 & $.538 * *$ & $.673 * *$ & .108 & .167 & $.543 * *$ & $.514 * *$ \\
\hline (8) Sat2 & .202 & .176 & .201 & .043 & .106 & .108 & $.538 * *$ & 1 & $.599 * *$ & -.059 & $.294 *$ & $.596 * *$ & $.537 * *$ \\
\hline (9) Sat3 & .107 & .181 & .198 & .042 & .177 & .101 & $.673 * *$ & $.599 * *$ & 1 & -.078 & .152 & $.488 * *$ & $.396 * *$ \\
\hline (10) GL1 & .184 & $.356^{* * *}$ & .132 & .125 & .008 & .082 & .108 & -.059 & -.078 & 1 & $.562 * *$ & -.075 & -.049 \\
\hline (11) GL2 & $.274 *$ & $.402 * *$ & .187 & .008 & -.006 & .164 & .167 & $.294 *$ & .152 & $.562 * *$ & 1 & .178 & .165 \\
\hline (12) DH1 & $.302 *$ & .114 & $.294 *$ & .113 & $.306^{*}$ & $.262 *$ & $.543 * *$ & $.596^{* *}$ & $.488^{* *}$ & -.075 & .178 & 1 & $.769 * *$ \\
\hline (13) DH2 & $.355 * *$ & .025 & .202 & .087 & .160 & .129 & $.514 * *$ & $.537 * *$ & $.396^{* *}$ & -.049 & .165 & $.769 * *$ & 1 \\
\hline Mean & I & 7.29 & 5.83 & 5.72 & 5.62 & 5.38 & 4.26 & 4.43 & 3.90 & 5.57 & 5.72 & 4.42 & 4.33 \\
\hline S.D. & 1 & 3.13 & 1.49 & 1.56 & 1.59 & 1.87 & 1.35 & 1.28 & 1.40 & 1.18 & 1.09 & 1.34 & 1.31 \\
\hline
\end{tabular}

Note: $* \mathrm{p}<.05 * * \mathrm{p}<.01$ 